Portland State University

PDXScholar

\title{
Developing a Language in Education Policy for Post- apartheid South Africa: A Case Study
}

\author{
Nancy Murray \\ Portland State University
}

Follow this and additional works at: https://pdxscholar.library.pdx.edu/open_access_etds

Part of the African Studies Commons, and the Bilingual, Multilingual, and Multicultural Education Commons

Let us know how access to this document benefits you.

\section{Recommended Citation}

Murray, Nancy, "Developing a Language in Education Policy for Post-apartheid South Africa: A Case Study" (1997). Dissertations and Theses. Paper 5345.

https://doi.org/10.15760/etd.7218

This Thesis is brought to you for free and open access. It has been accepted for inclusion in Dissertations and Theses by an authorized administrator of PDXScholar. Please contact us if we can make this document more accessible: pdxscholar@pdx.edu. 


\section{THESIS APPROVAL}

The abstract and thesis of Nancy Murray for the Master of Arts in Teaching English To Speakers Of Other Languages were presented on April 23, 1997, and accepted by the thesis committee and the department.

COMMITTEE APPROVALS:
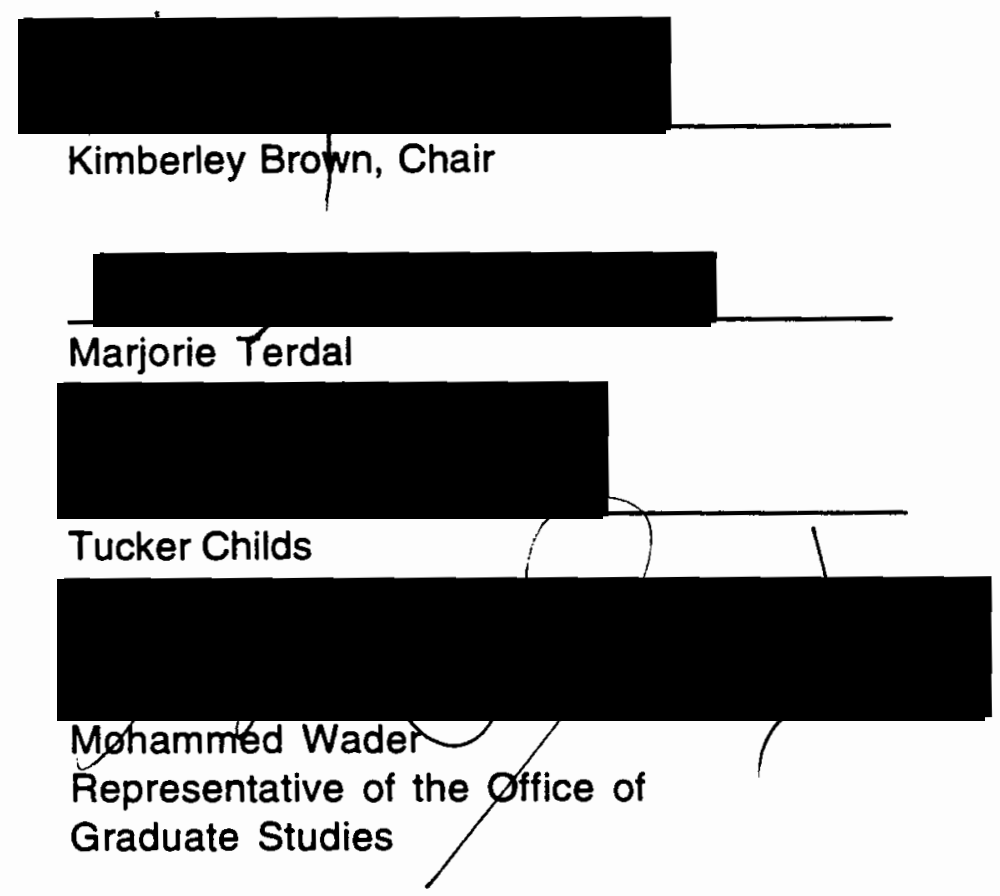

DEPARTMENT APPROVAL:

Marjorie Terdal, Chair

Department of Applied Linguistics

ACCEPTED FOR PORTLAND STATE UNIVERSITY BY THE LIBRARY

by

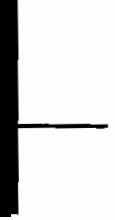

on

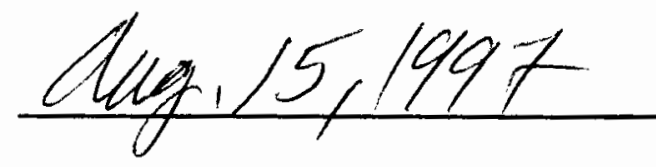




\section{ABSTRACT}

An abstract of the thesis of Nancy Murray for the Master of Arts in Teaching English to Speakers of Other Languages presented on April 23, 1997.

Title: Developing a Language in Education Policy for Post-Apartheid South Africa: A Case Study

The dismantling of apartheid laws, the all-race elections of 1994, and a new Constitution signal opportunities for fundamental change in South Africa's educational system and language policies. This study describes the development, still in progress, of a new language in education policy. The primary focus is on the various issues involved in the making of a policy--the assumptions and principles which provide the foundation for a new policy, the active participants in the policy debate and formulation, the perceptions of the role of English in South African society and schools, English as the medium of instruction, and possible consensus at the time of this study. Data for this research include school visits, interviews, and classroom observations in South Africa, and primary source material including government discussion documents and articles from professional journals and other South African publications.

English is widely regarded as a desirable medium of instruction despite the low rates of academic achievement by black students under the past educational system. There is consensus among government policy planners, language educationists, and non-governmental organizations active in the policy debate to support a multilingual approach to teaching and learning. Another 
important goal is the redress of the past neglect of African languages through greater utilization of African languages in schools. Proposed educational models use a multilingual approach with a choice of languages and flexibility in model design. English is a resource that should be made available to learners in an improved way that empowers all South Africans to participate in the social, economic and political life of their country. Policy making that involves democratic community structures on the local level will help assure that implementation plans are flexible, creative and appropriate to local situations, needs and aspirations.

Success of the nascent language in education policy will be affected by a number of factors which include the degree of involvement of the local education community in policy implementation plans, the provision of adequate resources, both human and material, to bring about needed changes, improved teacher training, government support for multilingualism in other institutions, and political negotiation on all levels. 
DEVELOPING A LANGUAGE IN EDUCATION
POLICY FOR POST-APARTHEID SOUTH AFRICA:

A CASE STUDY

by

NANCY MURRAY

A thesis submitted in partial fulfillment of the requirements for the degree of

MASTER OF ARTS
in
TEACHING ENGLISH TO SPEAKERS OF OTHER LANGUAGES

Portland State University

1997 


\section{ACKNOWLEDGMENTS}

This research project was born from an idea for a Fulbright-Hays Group Projects Abroad grant proposal: to take Oregon elementary and secondary school teachers to South Africa to study a culture in transition from a very troubled past where the majority of South Africans were denied basic freedoms to its first years as a nascent democracy. I thank Dr. Mathilda Harris for her encouragement and guidance in writing a successful proposal and to Mr. Ralph Hines, U.S. Dept. of Education, for seeing the worth of this project and selecting it for funding. Without this beginning the rest would not have followed.

Obtaining pertinent documents from outside South Africa was facilitated by several South Africans working in the field of teaching English and language planning. They were generous in their time to find and send articles and suggest other sources. The preponderance of materials was gathered by $\mathrm{Dr}$. Colyn Davies, Vista University and Alice Goodwyn-Davies of UNISA, and to them I am extremely grateful. Other contributors who provided important sources were Nigel Crawhall, Director, National Language Project; Kathy Luckett, researcher at the Centre for University Education Development at the University of Natal, Pietermaritzburg; Peter Plüddemann, Project for the Study of Alternative Education in South Africa (PRAESA); and Mike Smith of Heinemann Publishers.

The most powerful and enriching part of the research was the visits to schools and presentations by educators. I thank very much our host directors 
who provided rich cultural experiences that not only became important context for the readings about language policy but were cultural learning opportunities that few travelers to another culture are privileged to have. These hosts were Cheryl Heins, Vista University, Orange Free State, for the Johannesburg visit; Janet Thomson, Applesbosch Teachers College for our experience in rural KwaZulu/Natal; Mike and Juliet Hart, University of Natal, for the week in Pietermaritzburg, KwaZulu/Natal; and Mike Bam for our week in Nelspruit, E. Transvaal. My life is richer in experience and understanding for their contributions. 


\section{TABLE OF CONTENTS}

PAGE

ACKNOWLEDGEMENTS

LIST OF TABLES $\ldots \ldots \ldots \ldots \ldots \ldots \ldots \ldots \ldots \ldots \ldots \ldots$

LIST OF FIGURES $\ldots \ldots \ldots \ldots \ldots \ldots \ldots \ldots \ldots \ldots \ldots \ldots$

CHAPTER

I INTRODUCTION ...................... 1

Statement of the Problem . . . . . . . . . . . . 1

Background ...................... 5
Brief History of Education
Brief History of Language Policy
Some Consequences of Language Policy in Black Schools

Limitations of the Study . . . . . . . . . . . . . . 13

Research Questions ..................... 15

Definition of Terms ................... 15

II REVIEW OF THE LITERATURE ................ 20

Language Planning and Policy Issues . . . . . . . . . . 21

Theoretical Frameworks

Mother Tongue Education

Recent Policy Investigations in South Africa

Research into the Teaching and Learning of English in South African Schools and its Implications for Language Policy . . . . . . . . . . . . . . . . . . . 39 
The Threshold Project 1993 Teacher Survey

Arguments Favoring and Opposing English as Medium of Instruction . . . . . . . . . . . . . . 46

Arguments for English as Medium of Instruction Arguments for an African Language as Medium of Instruction

The Role of English in Other African Educational Systems

1st World Congress of African Linguistics

The Organization of African Unity

Summary ................... 55

III METHODOLOGY .................... 56

Data Collection ................. 58

Procedures . . . . . . . . . . . . . . . . 59

Data

Interviews

Observations

School Environments

IV FINDINGS $\ldots \ldots \ldots \ldots \ldots \ldots \ldots \ldots \ldots \ldots \ldots$

Șchool Visits . . . . . . . . . . . . . . . 63
A. Maritzburg College
B. Lowveld High School
C. Nelspruit Hoerschol
D. Wartburg High School
E. St. Charles College
F. Robben Island Primary School
G. Penryn College
H. St. Joseph Primary School
I. Montebello Primary School
J. Khwezi Junior Primary School 

K. Crocodile Valley Primary School
L. Mjele High School
M. Sikhulile High School
N. Woodhouse Primary School
O. Manguveni and Masibeka Primary Schools
Summary of school visits

Language Policy Discussions . . . . . . . . . . . . 92

Discussions preceding the 1993 Constitution 1993 Interim Constitution and Language Policy

Post-1993 Constitution Discussions

Other Contributors to the Language in Education

Summary

Policy Debate

Proposal and Models .

Kathy Luckett: National Additive Bilingualism

Neville Alexander: Multilingual Schooling

Kathleen Heugh: Modified Dual Medium

(1)

Return to Guiding Questions . . . . . . . . . . . . . 124

Suggestions for Further Research . . . . . . . . . 138

Implications for the TESOL Practitioner . . . . . . . 139

Concluding Thoughts $\ldots \ldots \ldots \ldots \ldots \ldots \ldots \ldots$

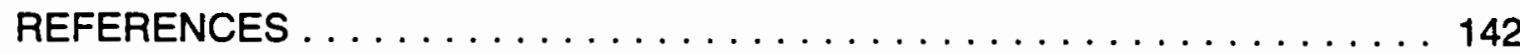




\section{LIST OF TABLES}

PACE

\section{TABLE}

I American and South African School Level Equivalencies . . . . . .19

II Alexander's Model of a Multi-Medium School . . . . . . . . . 120

III Heugh's Model for a Dual Medium, Multilingual School . . . . . .122 


\section{LIST OF FIGURES}

\section{PACE}

FIGURE

1. Per Cent of First Language Speakers in South Africa . . . . . . 14

2. Teacher Preference of Medium of Instruction . . . . . . . 45

3. Map of South Africa Indicating Areas of Schools. Visited . . . . 74

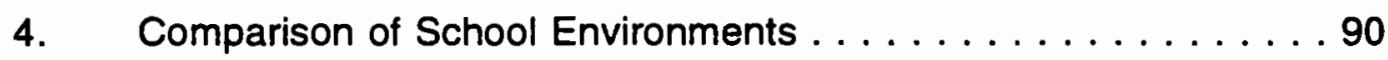




\section{CHAPTER I}

\section{INTRODUCTION}

\section{STATEMENT OF THE PROBLEM}

Like the continent of Africa itself, South Africa has been described as one of the most culturally and linguistically diverse countries in the world. And like other sub-Saharan African countries after independence, South Africa retained the dominant influence of the culture and languages of the Europeans who settled there. South Africa is unique, however, in the manner in which European languages and culture were manifested throughout the last 350 years, especially during the decades of apartheid law from 1948 when the National Party came to power until 1994. Political ideology played a central role in the system of education and in its language policy. Language became a gatekeeper to privilege and economic prosperity.

For the first time in its history, South Africa is a democracy with a constitution that grants civil rights to all its people. It has until recently endured a long period of severe repression of rights and privileges of the majority of its culture groups and imposed European systems, including its languages, English and Afrikaans (derived from Dutch). South Africa strives to continue its nascent peaceful revolution. Many changes are now in the planning stage to bring about long overdue racial equity--social, political and economic.

As part of the new Government of National Unity's move toward restructuring, or transforming the post-apartheid nation, in the 1993 interim 
Constitution and the 1996 Constitution, language choice has been acclaimed as a right of every person The change of status of nine major African languages to official status along with English and Afrikaans, previously the only two official languages, gives acknowledgment and protection to these eleven languages and cultures. The Constitution further declares that language rights include the "right of every person to establish, where practicable, an educational institution based on common culture, language or religion, provided that racial discrimination is prohibited" and the "right to instruction in the language of his or her choice where this is reasonably practicable." It also encourages the creation of conditions to develop and promote the equal use and enjoyment of all the languages (Republic of South Africa, 1993, in Heugh, 1995c, p. 44-45).

This study describes the development, still in progress, of a new language policy in education by a country in transition. The study will examine the development of a new language policy using original data from South Africa: articles in journals, magazines, newspapers, discussion papers, position papers, projects by research groups, interviews and classroom observations. The primary focus of this study is on the various issues involved in the making of language policy in education--assumptions and principles of a new language policy, the issues discussed in formulating the new policy, the perceptions of the role of English in South African society and schools, English as the medium of instruction, the active participants in language policy debate and formulation, and direction language policy is taking at the time of this study.

Policy drives many decisions which directly affect a student's experience in school, for better or worse. Student-teacher ratio, teacher preparation, text choices, per pupil funding, examination standards, language of instruction, 
and classroom facilities, to name a few, are all affected by policies formulated at some level of administration. It is evident from the research by educators in South Africa and my firsthand observations in schools that implementation of different educational policies for different races has resulted in a drastic gap between resources, learning environments and educational attainment of South African children.

South Africa is a country in a transition period, aiming to transform itself into a nonracial, democratic nation. I had the privilege to visit this country on a Fulbright-Hays Group Projects Abroad program in July-August 1995. I visited many diverse schools: urban and rural, private and state-supported, almost all white, more fully integrated and all black, and those well-equipped and very poorly-equipped to deliver well-taught lessons. The dismantling of apartheid laws in the early 1990's; the elections of 1994, and resulting changes in the administration of education are recent, so little has changed in most classrooms as yet. There is presently, however, a great deal of activity in educational and political circles to redress the inequities and discriminatory policies of the former education system under apartheid. As a researcher in the field of TESOL, I am interested to know how South Africa will meet this formidable challenge by focusing on one aspect that profoundly affects black students' learning: the language policy in education.

In the educational setting, language is, of course, far more than a vehicle through which students learn school lessons or communicate with the teacher. Language is also a powerful system of tools for use in the individual's construction of reality and a framework through which reality, as well as the individual's place in that reality is perceived. Culture groups use language to develop ideas and transmit meaning, modes of thought, and world views to 
future generations. Thus, the first aim of knowledge in any culture is its language. The chief objective of school is to encourage the mastery of the language of the culture, since without this mastery, children are denied power and influence over their own affairs and an opportunity for success in education (Hughes, Corson \& Caldwell, 1985). In South Africa, however, it was the white authority that determined the role that language played. Rather than empowering students, the English language requirements imposed on the black students in the school and university settings held students back and interfered with their intellectual and academic development (Smith, 1993).

Language is almost never the cause of social problems, but reflects social relations (Harlech-Jones, 1990; Paulston, 1994). South Africa's sociolinguistic complexity is due not only to the multiplicity of languages and cultures but also to their overlapping geographical distribution and the politicization of these languages and cultures during the colonial and apartheid past (Webb, 1994). The diversity of languages includes English, spoken throughout the country, by virtually all the different ethnolinguistic groups. There is a high level and degree of bilingualism and multilingualism despite the consequences of apartheid (Reagan, 1995). With a new democracy lacking a grassroots tradition, there are many questions as to how language policy will be formulated and by whom. South Africa is pursuing its goals of national unity and democracy by allowing time for all parties interested in language in education policy to consider the issues, debate the problems and possible solutions, and to determine a course of action.

In order to put the various issues and policy options under consideration into context, the following background is provided. 


\section{BACKGROUND}

\section{Brief History of Education}

The condition of the educational system today in South Africa is the result of political, economic and social forces inherent in colonial rule and in the continued impact of European culture and languages since South African independence early in this century. Before Europeans landed on the Cape in 1652, settled, and trekked further inland, African societies educated their young through informal, experiential ways which included tasks, stories, songs, poems, and oral histories. After Dutch settlements became established, more formal education was instituted for religious instruction but did not provide universal education, even for children of the Dutch trekboers (cattle farmers), and very little for blacks.

After the British took control from the Dutch in 1815, the schooling system became better organized but was still quite uneven, as there was neither a state system to provide free education, nor was education made compulsory. The British wanted to use education to spread their language and traditions as well as for social control (Christie, 1991). They declared English as the official language in social institutions and attempted to anglicize the church, government and schools. As the system became more complex with the growth of private schools, mission schools, state-aided schools and a few state schools, education not only was divided along racial classifications but social class as well.

After freeing slaves during the 1830 's, British government leaders saw education as a way to "raise the natives in Christianity and civilization" and "encourage them to follow industrious habits" (Christie, 1991, p.37). Cape 
governors were generally uneasy about giving higher education to Africans whom they saw as more useful to them as unskilled laborers. The vast majority of Africans did not have much education and did not have equal economic or political rights.

The development of mining, the Anglo-Boer War, and the movement to towns brought a period of social upheaval in the early 1900's. A highly significant step in the development of the South African educational system occurred when the British developed a system of free, compulsory education for whites but not for blacks. In doing this, they laid the foundation for separate school systems for blacks and whites.

Apartheid, the policy of extreme racial separatism and domination of the black majority, enacted into law by the Nationalist Government, created rigid racial segregation in education. There were no fewer than seventeen Departments of Education to maintain control over any potential development and alliances between subdominant groups (Squelch, 1993). One implication of this policy was that the South African population was compartmentalized into separate ethnolinguistic communities. Language planning was used to confirm the reality of racial separateness (Cluver, 1992). White education was controlled by four separate departments, one for each of the then-four provinces in South Africa. There were separate departments for 'coloureds' and 'Indians.' Black education was under the control of the Department of Education and Training (DET) and run largely by whites.

In addition to these seven departments was a department for each of the ten "bantustans," the government-created, so-called independent states, where black people were sent to live apart from whites. This fragmentation also resulted in duplication of services which was costly and divisive (Janks, 
1990). In each of the various ethnic homelands an indigenous language and English were used as official languages. The lingua franca that linked all these ethnic areas was English.

The educational provision was grossly unequal, preparing pupils for different forms of labor as intended by the government. Indeed, Hendrik Verwoerd, Minister of Native Affairs said, "There is no place for [the Bantu] in the European community above the level of certain forms of labour... For that reason it is of no avail for him to receive a training which has as its aim absorption in the European community, where he cannot be absorbed" (Janks, 1990 , p. 244).

Throughout the decades of this century there grew a vast disparity between racial and social classes. Education did not create this disparity in and of itself, but reflected the social relations within the country and the political will of the government. Besides access to educational opportunity, the South African ruling elite created many mechanisms to divide and oppress the various African cultural groups. Language policy was one mechanism.

\section{Brief History of Language Policy}

Language in education policy was largely influenced by three factors: the language of the government, the political agenda of the government, and the socio-political status of the speaker of any given language (NEPI, 1992). Bantu education was also predicated on a specific language policy, which formed an integral part of the apartheid ideology (Lemmer, 1993). The policy of English/Afrikaans bilingualism dates back to the 1910 Union Constitution which entrenched the language rights of the former colonial powers, namely the English and the Dutch, in South Africa. 
From 1930-75, language policy in black schools, which had favored English, sought to diminish the influence of English and promote the learning of Afrikaans, the language of the Nationalists, the dominant political group. The government financed various institutions to fully standardize Afrikaans, itself considered since early times to be a 'bastard' or 'kitchen' Dutch. Two aims of the political agenda of the government determined its language policy, the need to establish and maintain the Afrikaner as a separate cultural and linguistic group, and the need to establish and maintain the other ethnolinguistic groups in the country (Cluver, 1992). Mother tongue education proved to be an effective strategy in maintaining the ethnic identity of the Afrikaner and the speakers of indigenous African languages.

The Christian National Education (CNE) movement expressed the world view of Dutch-Afrikaner people and the education of its children. In 1948, it published a well-known pamphlet which stated:

We want no mixing of languages, no mixing of cultures, no mixing of religions, and no mixing of races. The struggle for the Christian and national school still lies before us. (Christie, 1991, p. 174)

To understand present day attitudes of blacks toward instruction in the mother tongue, it is important to consider the CNE view:

We believe that the teaching and education of the native must be grounded in the life and world view of the whites, most especially those of the Boer nation as the senior white trustee of the native, and that the native must be led to a mutatis mutandis yet independent acceptance of the Christian and National principles in our teaching. We believe that the mother-tongue must be the basis of native education and teaching but that the two official languages must be taught as subjects because they are official languages, and to the native, the keys to the cultural loans that are necessary to his own cultural progress. On the grounds of the cultural infancy of the native, we believe that it is the right and task of the state, in collaboration with the Christian Protestant Churches, to give and control native Education. (in Janks, 1990, p. 244-245) 
Until the Bantu Education Act of 1953, schools and universities were educating relatively competent speakers of English, though the numbers were very small (Wright, 1993). The 1953 Act separated black learners from native English speakers and destroyed most educational environments in which English competence could be developed. It left the English of black Africans to develop haphazardly in the townships. The Act legislated that mother-tongue medium of instruction be extended one year at a time up to Standard 6 (grade 8) in black primary education. In secondary school, students were forced to switch from the vernacular to English or Afrikaans in order to master increasingly difficult subject matter. Whatever the advantages of studying through one's mother tongue, the policy of delaying the introduction of English was interpreted by the black community as having but one powerful aim, the permanent and total subjugation of blacks to whites (Walters, 1996).

In late 1974, language policy in black schools became more inflexible, especially in the Transvaal province. The government initiated a requirement that students study math and social studies in Afrikaans. There was enormous resistance to this policy and to mandating mother tongue instruction. The resistance culminated in the Soweto Uprising of 1976 and in a broadened liberation movement, which, in turn, brought disastrous effects for the education of more than a generation of black students. The unpopular decision mandating Afrikaans was reversed by the authorities under pressure from the black community, and schools were given the choice of medium of instruction from Standard 5 (grade 7) onwards. The black communities overwhelmingly preferred English as medium of instruction in black schools. Eventually schools won the right to teach in English from Standard 3 (grade 5) to matriculation. This is the present system, in theory if not always in practice. 
Some consequences of lanquage policy in black schools

In 1985, Carol Macdonald and a team of researchers began a five-year study called the Threshold Project. It was set up by the Human Sciences Research Council to investigate the language and learning difficulties resulting from the change in the language, or medium of instruction in Standard 3 (grade 5), a policy known as delayed immersion. The results of an extensive array of tests showed that the present generation of junior primary children in Standard 3 could not handle the medium transfer. The children's language skills--oral, reading, writing, and listening--were poorly developed in both first and second languages (Macdonald \& Burroughs, 1991). During the first four years of primary school, children learned English as a subject, generally for thirty minutes a day. The Threshold Report found that the syllabus for English-as-a-subject did not provide a strong enough foundation for using English as the language of instruction for learning ten subjects from Standard 3 onward. Given the lack of a new syllabus, this is still the case.

There is a huge gap between what students are taught in Standard 2 and what they must know to succeed in Standard 3 when English becomes the medium and more content subjects are introduced. The difference can be illustrated by the 800 -word vocabulary attained through successful teaching and learning of English through Standard 2 compared with the 5,000-word core vocabulary needed in Standard 3 to cope with the new subjects (Macdonald \& Burroughs, 1991). This problem contributed substantially to the fact that only $77 \%$ of African children who started primary school finished it, and that only half of those who finished primary school did so within the minimum seven-year period (South African Institute of Race Relations, 1994). The National Education Policy Investigation (NEPI) researchers found that African students 
spent an average of eleven years enrolled at school, but the average attainment of African school leavers was equal to nine years of schooling (South African Institute of Race Relations, 1994).

Another important factor in teaching and learning affected by the change in language medium is the change in teaching style. In the first four years of school when children learn in their mother tongue, the teacher is the authority but also plays the role of the mother. There is a lot of group work, and children usually have the confidence to manage their own learning. When children begin learning in English, many positive parts of learning are lost. Teachers have less confidence teaching in English. Since students don't understand the difficult vocabulary of the texts, teachers must summarize in the mother tongue on the board. The teaching style becomes "chalk and talk" where the students no longer actively manage their own learning at the teacher's direction (Macdonald \& Burroughs, 1991, p.15-16). The children become passive learners, listening to the teacher talk and copying what the teacher writes on the chalkboard.

There are difficulties in teaching in a second language, another major handicap. The teachers know they are supposed to teach in English even though they also know the students will probably not understand if they do. If they teach a difficult subject, like geography or science, which requires understanding multiple concepts, then their teaching is not effective in the mother tongue because of the difficulty in matching concepts in two languages. Neither is it effective in English when students struggle with vocabulary and syntax to understand the concepts.

Teachers have not had the training in specific sets of skills to overcome these barriers to learning. Teacher training has not made teachers aware of 
the complex role of language in cognition, the construction of knowledge and the formation of individual and group identity (NEPI, 1993). Furthermore, those teachers who use English well in the classroom are rare (Macdonald \& Burroughs, 1991).

Lanham, of the University of Witwatersrand, did research with teacher trainees in Soweto while also attempting to help them improve their students' English. In just eight years since the formal enactment of the Bantu Education Act of 1953, competence in English was already in decline. For example, 153 of 178 trainees could not correctly name the hands of the clock. In 1967, Lanham found that with a number of trainees tested, "the simple enquiry: "Where did you go to school?' had to be recast and repeated several times before it was understood" (Lanham in Walters, 1996, p. 214).

In a multilingual, multicultural school setting, which is becoming more common now that white schools have opened up their enrollments to blacks, ethnographic research has found that black students experience alienation from the dominant culture of the school, from their home cultures and from pedagogical practices in the classroom (Gordon \& Barkhuizen, 1994). These practices, including unspoken assumptions regarding the purposes of education and what constitutes appropriate interaction in school among students and between student and teacher, create alienation of black students from the culture of the classroom. Black students also experience alienation from opportunities to learn because of the "English only in the classroom" rule where direct translation into mother tongue is not allowed. They are also alienated from positive reinforcement, because students are reluctant to answer in front of class in a second language. 
Another important consequence of the English-only mandate is the marginalization and stigmatization of African languages. Though Figure 1 shows how few speakers of English there are in relation to those of African languages, there exists an imbalance of high status favoring English with a corresponding low status of African languages. As a result of language policy in education, there are not the parallel selection of texts and literature in languages other than English and Afrikaans. Another detraction of the use of mother tongue education, according to Guy Bostock of Fulcrum, an organization that provides language teacher training, is that "the [African language] syllabus is not interesting at all and needs a massive effort to rewrite it. An exciting course would produce excited kids" (personal communication, August 1, 1995).

\section{LIMITATIONS OF THE STUDY}

There are many important issues in the policy discussion of this large and complex language problem which are mentioned here but are not a focal part of this study: the role and development of indigenous African languages, the role of Afrikaans, consideration of a standard of English, multicultural education, teacher preparation, and English teaching methodologies, dealing with the effects of learning through a non-native language on cognition. This study is concerned with language in education in the primary and secondary school phases, but not at the university level. Further, this study does not claim to have found every source which has published an opinion or position on the topic of a new language policy in education. 
Figure 1. Per Cent of First Language Speakers in South Africa
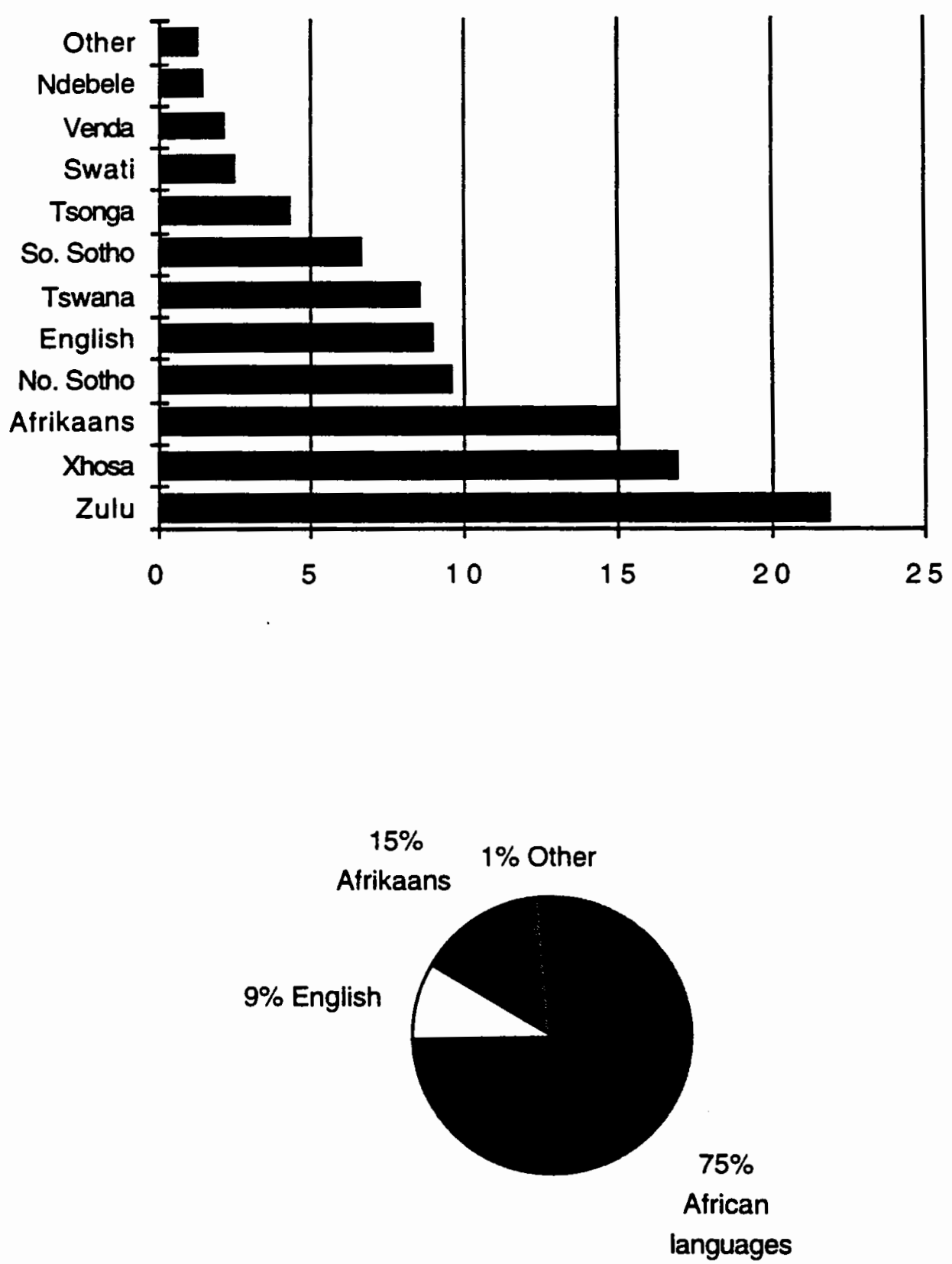

Source: Dept. of Education, Republic of South Africa, 1994 


\section{RESEARCHQUESTIONS}

The main inquiry for this study is:

Given the government's awareness of the need to address the issue of languages in education and to improve the learning outcomes for students where it is clear that established language policy is contributing to educational failure, what are the issues in the current language in education policy debate? What direction is the government planning taking?

Following are guiding questions:

1. What are the attitudes towards English in school?

2. What do the school visits in this study reveal about language in education issues?

3. Who are the participants in the language policy debate?

4. What are the principles being set forth upon which a new language policy will be framed?

5. What models or options are being proposed, and what are their stated benefits and possible disadvantages?

6. What consensus is emerging, if any?

7. What factors will affect the success of a language in education policy?

\section{DEFINITION OF TERMS}

Heeding Tollefson's (1991) charge that social science researchers too often distance themselves from the 'humanity' of the subject they are 
researching by referring to people in terms such as 'populations' and 'variables', I have made a conscious effort to use words which do not hide the individual person in terminology that removes his or her particular life as it has felt the impact of policy decisions and lack of educational opportunity.

Because the policy studied is South African, I use terminology concerning persons and institutions as they are referenced in South African literature. A definition of terms and some explanation in the text are provided to give a rough equivalent for readers unfamiliar with South African culture and education or English language teaching terminology. Racial classifications are inherent in the discussion of South African education, both historically and in the present efforts to redress past inequities. Their use here recognizes those children whose future educational opportunities are currently under discussion and to emphasize their unmet particular needs as opposed to general references to all school children who have universal educational needs.

\section{Terms}

additive bilingualism: a form of bilingualism in which the person's first language is maintained while adding competence in another language.

Afrikaans: a language that developed from 17th C. Dutch in South Africa Afrikaner: an Afrikaans-speaking descendent of the Dutch settlers of South

\section{Africa}

ANC: African National Congress; the oldest and largest black political party opposing white minority rule. The ANC assumed power at Nelson Mandela's election in 1994.

apartheid: the institutional regulation of white domination over the black majority under the National Party government from 1948 to the 1994 
election.

Bantu: a member of any of several tribes of eastern, central and southern Africa; a group of Niger-Congo languages spoken in these regions.

DET: Department of Education and Training which, until the elections of 1994, was in charge of the administration of black schools outside the 'independent states' or 'Bantustans' that had their own administration. Formerly called the Dept. of Bantu Education.

immersion program: an educational model where learners are educated through $L 2$ for the purpose of bilingualism and cultural enrichment. $L 1$ is maintained throughout schooling.

language planning: deliberate efforts, which are ideological in nature, to influence the behavior of others with respect to the acquisition, structure, standardization, and function of language varieties, and can include allocation of functions to particular languages.

language policy: a set of principles conceptualized within an overarching framework of values; the goals of language planning. To be effective the policy must be congruent with the country's national development plan and with the will of the people.

lingua franca: a lingua franca is used when different speech communities are in continuous contact and need a common language for communication. medium of instruction: the language used in both the teaching and learning processes in a given educational institution; also called 'language of learning.'

mother tongue: it is the language that a person learns first and/or chooses to identify with; also commonly referred to as the home language, first language (L1), or vernacular. 
Standard 3: equivalent of American grade 5 in primary school and the most typical time when the medium of instruction is switched to L2, most often English. See Table I for American and South African equivalencies. straight-for-English: a term used in Anglophone Africa for a model where speakers of languages other than English begin and continue schooling in English. A submersion model where the first language is not adequately supported.

submersion program: an educational model where speakers of indigenous or immigrant languages are instructed through the medium of $L 2$, resulting in the dominance of that language at the expense of the mother tongue, which has little or no support. This is still the most common way of education for indigenous or immigrant (linguistic) minorities.

subtractive bilingualism: a process whereby the first language, seen as having little educational value, is removed from the educational environment of the student.

transformation: the reorganization of social, political and economic institutions based on a wholly different set of underlying principles and values. transitional bilingualism: a subset of subtractive bilingualism in that the first language is replaced by another language perceived to have greater educational importance, but allows for initial instruction in the first language. 
TABLE I

AMERICAN AND SOUTH AFRICAN SCHOOL LEVEL EQUIVALENCIES

American

Primary School (typical)

Grade 1

Grade 2

Grade 3

Grade 4

Grade 5

Grade 6

Secondary School

Grade 7

Grade 8

Grade 9

Grade 10

Grade 11

Grade 12
South African

Primary School

Grade 1, also Sub A

Grade 2, also Sub B

Standard 1

Standard 2

Standard 3

Standard 4

Standard 5

Secondary School

Standard 6

Standard 7

Standard 8

Standard 9

Standard 10, also Matric 


\section{CHAPTER ॥}

\section{REVIEW OF THE LITERATURE}

The articles, surveys and studies reviewed in this section are those that inform and contribute to the discussion of the development of South African language in education policy. Within the scope of my guiding questions, I selected these articles and studies based on their relevance to the situation in South Africa today, and their availability to me.

Because language issues are embedded in social, political and economic situations and, therefore, have important ramifications far outside of the classroom, it is usually the government rather than educators who uses its considerable power to set specific policies regarding language issues in schools. South Africa is a prime example of its colonial, post-colonial and apartheid-era governments making top-down decisions regarding languages used in school. Educational policy has long been characterized by centralized decision making. Until 1992, there was no consultation with parents about what languages were taught or used as mediums of instruction (NEPI, 1992). None of the values underlying past policies are congruent with the values of the present democratic government which seeks an equitable education system. There is a growing body of literature, both inside and outside South Africa, concerning language planning and policy. In this chapter, I review theories and issues discussed by several authors frequently contributing to, and cited in, the South 
African literature on language policy, in order to offer various perspectives of this complex topic.

The review of the literature is divided into four sections: language planning and policy issues; research into the teaching and learning of English in South African schools and its implications for language policy; arguments favoring and opposing English as the medium of instruction; and the role of English in other African educational systems. The literature reviewed here, taken together with the background information in Chapter I, attempts to provide a framework in which interested researchers can examine the pertinent issues and assess the principles, values and policy options promoted by those addressing language policy in South Africa today. In Chapter IV, policy issues raised by individuals and groups will be presented.

\section{LANGUAGE PLANNING AND POLICY ISSUES}

\section{Theoretical Frameworks}

Language policy issues are multi-faceted as they relate to various and ever-changing dimensions of the social fabric of a nation. In this section I bring forward views from a number of authors who write about language policy to provide a broad context in which to understand the complex nature of this topic.

In order for a language policy to be successful in accomplishing stated goals, policy makers and language planners who design the implementation phase of the policy should define the criteria which are critical to meet. Hughes, Corson and Caldwell (1985, p. 27) offer the following criteria for a language policy: 
1. the policy should identify the national needs for its languages

- available resources need to be surveyed,

- roles of languages in general, and individual languages in particular, in the life of a nation should be identified,

- strategies necessary to manage and develop language resources need to be established, and

- the resources, roles and strategies need to be related to the best interests of the nation through the operation of an appropriate planning authority,

2. the policy should be comprehensive, taking all relevant information into account, and be

- consistent, so that one aspect doesn't work against the others,

- founded on and consistent with other social goals society sets for itself, and

- acceptable to the population.

Heugh (1995, p. 332), along the same line of thinking, offers four assumptions upon which the implications of language policy can be measured:

1. if the language policy does not match up with the explicit goals of the state, the one is likely to undermine the other,

2. if effective language planning procedures are not put in place, the policy will not be implemented,

3. if the language policy is in conflict with the more hidden political and economic infrastructure, the policy will be undermined, and

4. if the articulation and implementation of language policy are entirely topdown rather than accommodating bottom-up processes, then the needs of the people will not be met.

Another framework in which to view language, which also affects language planning efforts, is through one of three orientations: language as a 
problem, language as a right, or language as a resource (Ruiz, 1988). An orientation consists of both one's disposition towards a language and towards its role in society. The orientation is related to language attitudes in that it frames how we talk about language, the basic questions we ask, and the conclusions we draw from the data.

Ruiz sees most language planning activities based on seeing language as a problem. For example, language diversity is viewed as undermining national unity with multilingualism being seen as a problem. Seeing language as a right is important to give short- term protection as well as long-term guarantees to marginalized languages. A drawback to this orientation is the widespread response of non-compliance, usually due to many inherent inconsistencies and conflicts of interests, such as individual versus group rights.

Viewing language as a resource means viewing it as a social resource. Policy implemented in this orientation would preserve, manage and develop all South African languages. A benefit to viewing language as a resource is its potential to help ease tensions between minority and majority communities and to highlight the importance of cooperative language planning. In education, this orientation promotes additive bilingual programs, which would accommodate students who speak languages different from the medium of instruction.

A look at language policies in multilingual nations can produce useful generalizations as well as very different solutions to similar language problems. What can be learned from the study of the experiences of other countries and what were the conditions in which the language policies were applied? Paulston (1994) makes some general points which help frame this complex topic in her comparative study of language policies through case studies, her own field work, and examination of others' case studies. 
When ethnic groups have prolonged contact there are three major possible linguistic outcomes: language maintenance, bilingualism (including the spread of a lingua franca), and language shift, where one or more languages become marginalized due to the power of another language. Paulston asserts that to understand language policies that aim to regulate the interactions of ethnic groups within the modern state, one must understand language maintenance and shift and the social conditions under which they occur. The problem facing policy makers is that, at present, we have a very poor understanding of what the relevant social forces are and what the corresponding educational, social and cultural outcomes will be.

Paulston points to two examples of this dilemma. Hebrew was successfully revived largely due to the prevalence of necessary social conditions and religious attitudes, and it succeeded without any formal language planning. Peru's policy, on the other hand, making Quechua an official language, failed resoundingly upon implementation. Policy makers there failed to recognize the socio-economic stigmatization of the Indian culture as a force which would affect the success or failure of a language policy. These examples also underscore her point that schools and schooling can facilitate social trends, but they cannot successfully counter social and economic forces on their own (Paulston, 1986).

Harlech-Jones (1994) makes further observations in line with Paulston's findings. The former suggests that a general analysis of language policies in much of sub-Saharan Africa reveals a lack of conspicuous success partly due to several factors outside the immediate control of the state. These include the degree of social stratification, unequal distribution of wealth, mobility within a society, and the extent of available educational opportunities and quality of 
instruction. Harlech-Jones argues that the lack of success is also due to policies being based on flawed principles, resulting in the following:

1. Language planning has occurred in an isolated context as if it is the causal factor in social change and impervious to economic, social, historical and other factors. In fact, if it is not coordinated with many other significant factors, it will not succeed in achieving the stated reforms.

2. Policies were set, often in official documents, and pursued without much, if any, reflection. In contrast to recommendations by scholars concerned with policy making and implementation, most African countries have not revised their inflexible policies since independence. Since language policy should be taken in context with many factors that change over time, flexibility and review should be anticipated and built into the policy and its formation. This is also consistent with the ideas expressed below.

3. Policies have been aimed at the realization of ultimate and distant political aims. This is a consequence of the authoritarian and undemocratic rule that has afflicted African countries before and after independence. Language policies have been elitist and contributed to the widening of social stratification rather than integration. Instead of aiming at particular language problems, the policies were aimed at social engineering an ideal (e.g. nation building, democracy, modernization). Ideals can be difficult for people to conceptualize and rally around, and there are many who agree with Popper's recommendation (as cited in Harlech-Jones, 1994) that we reach for modest ends by adopting a piecemeal engineering approach to solving identified problems, "the greatest and most urgent evils," rather than devising a blueprint about social engineering to attain an ideal society (p.12). 
In 1990, one of the twelve groups of the National Education Policy Investigation (NEPI) project focused on language. It acknowledged that development of theories concerning language policies and how they affect social, economic and political situations is still at an early stage. From the responses they received on discussion documents circulated, NEPI researchers believed that though there were strongly held views about language policies, the issues and their complexities were not yet widely understood in South Africa.

In looking for theoretical frameworks that would inform policy analysis in South Africa, NEPI researchers drew primarily from the works of Tollefson (1991) and Cooper (1989). In his book, Planning Lanquage, Planning Inequality (1991), Tollefson urges language professionals to explore the ideological foundations of the theories and practices which underlie their country's language policies. Policies that appear to be founded on common sense and irrefutabie assumptions are very often based on beliefs accepted without scrutinizing and making explicit the values embedded within those beliefs. Tollefson suggests that language policy is much more involved in people's daily lives than one might realize.

The researchers assembled views about language they have heard expressed from a wide spectrum of people and formed them into eleven propositions (NEPI, 1992, p. 3), which are listed below in italics. Because of Tollefson's acknowledged influence on NEPI's research and discussion, I include some of his central positions and theoretical constructs as they relate to the South African views about language expressed below. Tollefson's central premise is that there is a close association between language policy, power and privilege. 
1. (English) does not have the negative image that Afrikaans has in some circles as 'the language of the oppressor'.

Tollefson states that language policy is a powerful tool for exclusion and is fundamental for exploitation (p. 210). Hierarchical social systems are associated with exploitative language policies, those policies that give advantages to speakers of particular languages. South African history illustrates Tollefson's points.

2. A lingua franca would facilitate the development of national unity.

Tollefson notes that conflict is seen as the result of linguistic diversity instead of unequal political and economic structures. As will be discussed later in this chapter, in the 1960's, many newly independent African nations used this view of the unifying benefit of a lingua franca as a premise in the nation building ideology of that time. But without significant attention paid to transforming colonial political and economic structures, the vision of national unity failed to develop. Tollefson would attribute this failure to his position that language policy is inseparable from the relationships of power that divide societies and that policy must be seen within the context of its role in serving the interests of the state and the dominant groups. On the positive side, he maintains that language planning can be used to transform relationships of power.

3. It would be sensible if the lingua franca were to be either English or Afrikaans, the languages that are currently used in advanced financial, commercial, technological and academic fields, as this would broaden access to these fields.

Tollefson supports the theoretical construct of an historical-structural approach which attempts to explain how language is used to determine which individuals and groups have access to political power and economic resources. 
Proponents of this theory conclude that the educational system is largely irrelevant to the processes that determine the economic fate of non-English speakers, and that schools will be unable to resolve their economic problems. 4. Of these two, English is the better candidate because it is the language of access to the wider world.

ESL teachers are agents of 'modernization' to developing countries and claim to empower the people, but Tollefson asserts that they help sustain existing power relationships. Becoming modern implies importing Western technology and building economic ties with the West, for which it is assumed that English is an essential tool. Language educationists must reject the notion that learning a language is solely for the purpose of developing a skill for employment and an ideologically neutral act. That some people must learn English in order to get a job is the result of unequal power relationships, not a solution to them.

5. None of the African languages could serve the functions the current official languages serve because they are underdeveloped. Nor could they be media of instruction at the post-primary level for the same reason.

Modernization theory asserts that 'underdevelopment' can best be overcome by adoption of institutions and patterns of behavior like those found in industrial societies. This theory would support the requirement of a single dominant language, i.e. English, to acquire a modern information system of science and technology. Alternately, the assumption is that 'undeveloped' languages, those that don't have vocabulary for science and technology, could not serve in this capacity and should be abandoned in favor of a developed language such as English. Tollefson is among the critics of the modernization theory and associates the spread of English with inequality within 'developing' societies. A developing society is characterized by the presence of a 'Western' 
(developed, industrialized) sector and a 'traditional' ('underdeveloped,' preindustrial) sector. Members of the 'traditional' sector often do not speak English because it is spread inconsistently, and many do not have meaningful access to it. Tollefson concludes that inequality in the spread of English is not responsible for the unequal distribution of wealth, but it helps to institutionalize the gap between sectors and establish a practical barrier to those who want to move from one sector to another (p. 85).

6. Because South Africa is a multilingual country, it needs a lingua franca. 7. All children should learn English (or Afrikaans) at school.

8. Having English (or Afrikaans) as the medium of instruction would be beneficial as it would vastly increase children's exposure to the language in terms of both time and domains of use.

9. Children should start as young as possible because they learn languages better when they are young.

Culture contact theory, which includes language learning, asserts that minority students can overcome inequalities through curricula and teaching practice. Tollefson and other critics suggest that the theory is part of an ideology that sustains inequality. The theory assumes that overcoming inequality is a matter of individual ignorance, which can be overcome through education, rather than the effect of historical and structural factors that are overcome only through political struggle. Therefore, the emphasis on language education as the key to economic and social justice risks oversimplifying the problem. An alternate view to culture contact theory is that inequality is rooted in the system and social structure, which is reflected in the education system and is, therefore, not able to be changed by it. 
10. This would also help in unifying people as it would promote an understanding of other cultures.

11. To even out the linguistic burden somewhat, children whose home language is the medium of instruction should have to learn an African language.

Another facet of culture contact theory holds that prejudice and discrimination by members of the dominant culture will be reduced if they study that language and culture. In fact, an extensive review of research in this area finds little empirical support for this belief. Culture contact has little impact on prejudice or minority school performance. Respect for diversity is important in addressing linguistic inequality, but it is inadequate because it locates the problem with the individual or ethnic group rather than the social structure.

Cooper (1989) looks at the nature of language planning, and his views mesh with those expressed here by Paulston and Tollefson. Though there is no universally accepted definition of language planning, Cooper asserts that it cannot be understood without reference to its social context. Regardless of the language problem to be solved, it is not a problem in isolation within the region or nation but is directly associated with the political, social, economic, cultural and/or religious situation. As such, Cooper sees language planning not as efforts to solve language problems but rather as efforts to influence linguistic behavior.

Cooper considers a number of challenges and hurdles at the outset of policy making: agreement on the exact nature of the language problem, finding the time and energy to examine all possible alternative solutions, choosing a solution on a cost-benefit basis that serves all groups fairly, and having the ability to calculate and predict the consequences of the possible solutions. Since language planning rarely conforms to a rational paradigm of decision 
making or problem solving, Cooper suggests that policy makers must rely on rules of thumb or standard operating procedures that keep decisions within the bounds of political and economic feasibility.

For a new policy to succeed, policy makers must be aware that neither those inside or outside the elite circle are likely to embrace new initiatives unless they perceive it in their own best interest to do so. Those policy alternatives that are consistent with the values and beliefs of the school communities the policy is designed to serve are more likely to succeed than those policies which conflict with those values and beliefs.

Another framework in which to view the complexities of language policy is to look at various approaches of political, economic, and social structures which would support certain policy orientations. Heugh (1995) groups these structures into four categories: segregation, assimilation, integration, and multiculturalism or interculturalism.

Segregation, the separation of groups in the divide-and-rule mold of the apartheid era, results in one group always having more power than the others. One language of high status, or possibly more, would be used to exclude speakers of low status languages from power. This structural orientation has led to the status quo in South Africa today.

An assimilationist structure has a dominant group with the subordination of marginalized groups under it. Though groups would be drawn together, the whole is hierarchical. Marginalized groups are always at the disadvantage of the culture, language and value system of the dominant group. If language policy makers accord equal status for the eleven official South African languages but fail to implement effective strategies to raise the status of 
African languages, then the status quo will remain. English will occupy the most-privileged status and other languages will have secondary status.

An integrationist structure establishes a system in which all groups and their languages, cultures and values coexist independently. This is the usual statement of policy of post-independence African nations, if not in implementation (Heugh, 1995). In order for this approach to take hold in South Africa, language use would need to treated as a positive right (after Desai and Trew, in Crawhall, 1993), that would be upheld proactively rather than passively.

Multiculturalism is what Alexander (Alexander \& Smolicz, 1993) refers to as core culture. It is a core of values and practices to which every South African has access, regardless of the language group he or she belongs to, which becomes larger as it is fed into by the various ethnic groups, or subcultures. Heugh (1995) sees this approach as "a radical social-transformative perspective" (p. 330). Complementary strategies in the political, economic, and educational sectors would rehabilitate African languages, and functional uses of languages would be acknowledged and fixed. English would be a lingua franca from an instrumentalist point of view, but with the possibility of another South African language serving in that role in the future.

After reviewing recent literature on international language policy, Heugh (1995) hypothesized that there is a relation between segregation and the view that language is a problem, between assimilation and the view that language is a problem, between integration and the view that language is a right, and between multiculturalism and the view that language is a resource. 


\section{Mother Tongue Education}

Language plays a central role in the development and modernization of a country, because it is the key to knowledge, information and communication. In addition, language can be a factor providing or withholding access to education and can become the major element in elite formation or continuation and alienation of groups of people.

Mother tongue language use is the expression of the primary identity of a human being. It is the language through which a person perceives the surrounding world and through which initial concepts are formed. Children establish their kinship with others and anchor themselves to their culture through socializing into its system of beliefs and practices through their mother tongue. Its loss results in a "loss of rootedness in traditions, intellectual impoverishment and emotional sterility" (Pattanayak, 1985, p.7). Studies of Spanish American children in America are similar to the experience of immersion programs in Canada researched by Lambert and Tucker in 1972, and show that initial mother tongue education not only gives greater coping ability but also leads to better conceptual development of children. Furthermore, the language of the dominant culture develops in meaningful dimensions in a child anchored in education in the mother tongue (Pattanayak, 1985).

There is evidence in Africa that negative attitudes towards one's own language has led to extinction of languages (Pattanayak, 1985). Some consider their mother tongue as a barrier to upward mobility, but for others it is the only key to equality of opportunity. These considerations may very well be based on achievement, but there are many other variables that affect achievement besides language choice, such as the socio-economic status of the children, school climate, methods of teaching, materials, and teaching ratio. 
Researchers Phillipson, Skutnabb-Kangas and Africa (1986) contend that overuse of colonial languages and underuse of mother tongues as mediums of education reproduce inequities, perpetuate elites and promote dependency on the cultures speaking languages of wider communication. They studied four program models: segregation, mother tongue maintenance, submersion and immersion. Factors contributing to the outcome were L1 or L2 as medium of instruction, status as minority or majority group, high or low status groups, and the language's designation as 'official' or not. The conclusions were that, in all successful contexts, the linguistic goal was bilingualism and the societal goal was a positive one for the group concerned. The mother tongues of the groups have been standardized and teaching materials were available. An example is Uzbekistan, where the societal goal is equity and integration, and there is maintenance of seven main languages in education.

Low levels of success were found in programs where the linguistic goal was primacy of one of the languages, not bilingualism. The other languages were neglected or badly-taught, even if they were standardized and had official status and teaching materials. In the unsuccessful programs, the larger societal goal was to keep the group or the bulk of the group in a powerless, subordinate position.

Zambia is an example of a country with a low level of success from its language policy. Its schools use a submersion program through its former colonial language. This is typical of other African countries where English is dominant for the elite and where the schools do not develop the mother tongues spoken by the masses. For the vast majority of Zambian students, linguistic and academic results are poor. After nine years of schooling in English, children still could not use English outside the classroom (Smith, 1993). 
English, children still could not use English outside the classroom (Smith, 1993). Children did better attaining literacy in L1 first, but they still needed highly competent teachers because they need lots of support in English. Education since independence has not mended this failure.

In South Africa, the Bantu Education Act of 1953, which marked the departure of the missionaries from education and the start of apartheid education, provided for the compulsory use of the mother tongue as the medium of instruction in junior primary school. Today, mother tongue education is associated with the apartheid regime and the lower status of the African languages. It is often seen as a strategy of the government to prevent the upward mobility of Africans, so that they remain a source of cheap labor.

In a study done on language preference among speakers of English, Afrikaans and Xhosa by two social psychologists from the University of Cape Town (Louw-Potgieter \& Louw, 1991), the researchers found that mother tongue instruction throughout the school career was rejected vehemently. Researchers found this preference unsurprising given South African educational history. However, dominance of a single language, even if it were an international language such as English, emerged as an unpopular choice among the majority of the three groups of respondents, who consistently opted for choices indicating tolerance of bi- or multilingualism.

At a bi-racial girls primary school in Port Elizabeth in 1995, a two-year pilot Xhosa language program was set up with the help of The Project for Alternative Education in South Africa, a non-governmental organization (NGO) dedicated to innovative approaches to teacher education and language learning. Even though the program was aimed mainly to teach Xhosa to English $L 1$ speakers, teachers recognized the importance of the program for Xhosa L1 
speakers in maintaining their language as a vehicle for cognitive development and building self-esteem. Staff reported an overwhelmingly positive response to the language program from all the children. However, according to the 1994 survey preceding the program, less than half of the Xhosa-speaking parents regarded L1 support for their children as important (Plüddemann, 1995).

\section{Recent Policy Investigations in South Africa}

In 1990, the National Education Policy Investigation (NEPI) pursued research of policy options for improving education in South Africa. The National Education Co-ordinating Committee, who commissioned this investigation, is a national body representing teachers, parents and students mainly from disadvantaged black communities. NEPI is an outgrowth of People's Education, which embodied the ideal of non-racist, non-sexist and democratic values of various organizations making up the democratic movement.

Twelve research groups were formed in such areas as adult education, curriculum, systems and structure, educational planning, and language. After twenty months, their efforts and deliberations resulted in a final report designed to frame the issues as a basis for community discussion and debate. This policy investigation came at a crucial time of political shifts in 1990, when then-President de Klerk inaugurated liberal reforms but had not yet given way to a transitional arrangement which would lead to reconstruction. Those who had had to use the strategies of opposing political forces and demanding reforms now needed to add new strategies such as employing public discourse and free debate. As a result, NEPI researchers pursued policy analysis as their 
aim and recognized that "notions of policy analysis and vigorous democracy are closely allied with each other" (NEPI, 1993, p.4). A further consequence was that it broadened the base of expertise in policy issues.

NEPI planners distinguished three broad processes:

1. Policy option analysis- best done by education analysts who have access to local and international information. They compare strengths and weaknesses of various options. Education practitioners also have an important role to play here, because they have a feel for the viability of various options.

2. Policy proposal (advocacy)- done by a constituency which has a stake in the future system such as the government, labor, business, political parties or lobby networks, such as education practitioners. Their aim is to win support for a particular policy.

3. Policy planning- an extension of policy proposal undertaken by policy administrators and significant policy players to formulate concrete implementation plans.

These three processes overlap with both the significant players and the execution of each stage of the process. NEPI's premise submitted that vigorous public debate from the interaction of the three elements was the best means of ensuring the legitimacy of a future education system which "reflects and serves popular aspirations" (NEPI, 1993, p. 14). Also critical to the success of policy making is a broad understanding of the issues and acceptance of the inevitable compromises.

Politics and values permeate the entire domain of policy consideration. NEPI concedes that though in democratic societies these three processes are interlinked and form a continuum, in South Africa they have become distinct and 
ossified, because state educationists are steeped in implementation and inexperienced in policy analysis.

Another challenge facing the investigation researchers was that, even though the differences between the development strategies of the major players within and opposing the government were clear, such as free market economy proponents vs. democratic planned economy supporters, those strategies were not detailed or defined. Thus, policy analysts could not draw linkages between macro-economic policies and the education policies that would be guided by them. For example, policies aimed at meeting popular demands for equality in some spheres tended, given scarce resources, to contradict policies geared toward short-term economic development or growth, even when the latter were aimed at producing the means to achieving equality in the future.

Using the guiding principles of non-racism, non-sexism, equality, democracy and the redress of historical injustices, NEPI (1993) asserted that the major issue in language in education policy is how the language policy contributes to:

- redressing past inequities and injustices with regard to access to education, - shifting the balance of power away from white middle class speakers of English and Afrikaans,

- preparing South Africans to use one another's languages in all areas of life, - ensuring all South Africans have access to English (currently the language of access to education and the established lingua franca) without jeopardizing the use of African languages.

NEPI researchers were very concerned that citizens be protected from linguistic disenfranchisement and acknowledged conspicuous disagreement 
existed on how to prevent it. They concluded the best way that was relevant to education was to extend access to languages of wider communication to everyone and to extend the use of African languages in public domains. While they had several reservations about placing emphasis on promoting access to English in the short term, they did not feel it was mutually exclusive to the goal of increasing the use of African languages.

\section{RESEARCH INTO THE TEACHING AND LEARNING OF ENGLISH IN SOUTH AFRICAN SCHOOLS AND ITS IMPLICATIONS FOR LANGUAGE POLICY}

\section{The Threshold Project}

The Threshold Project, conducted under the auspices of the Human Sciences Research Council over four years from 1985, examined the nature of language and learning difficulties that black Standard 3 (grade 5) children experience when they change from their mother tongue to English as a medium of instruction and learning, a policy known as "delayed immersion." The findings of this research are broadly summarized in Chapter 1.

Carol Macdonald, lead researcher and author of the final reports of this project, found that the results of their research had implications for the development of a language in education policy (Macdonald, 1990, 1990a). In order to predict the likelihood of success of a policy, Macdonald used the framework designed by Phillipson, Skutnabb-Kangas and Africa (1986), referred to earlier in this chapter. This framework considers sixteen points covering four broad ranges of factors. In every one of the sixteen factors that Macdonald interprets in the present South African context, black education falls short and has a "low degree of success." This, then, points to choosing a 
different model which would have a higher likelihood of success, and Macdonald presents five possible bilingual models (Macdonald, 1990a):

1. immersion model: While successful in some contexts such as Canadian primary schools, this policy in Anglophone Africa, where it is also called "straight-for-English," is by and large a failure due to children's lack of literate backgrounds, a lack of parental and cultural-environmental support for learning the L2, and lack of qualified teachers. (Other educationists have categorized straight-for-English programs as submersion programs.)

2. delayed immersion model: This is the present model in most schools where students study English as a subject for four years and then abruptly change to English as the medium of instruction for learning most content subjects.

3. gradual transition model: The change from L1 to $L 2$ is phased in with specific subjects over a period of years. With this model, longer term gains in English are made than in the immersion or delayed immersion models.

4. dual medium model: This is not in policy anywhere but is the de facto situation where teachers and students cannot deal with the L2 medium and must support the target language with the mother tongue.

5. submersion model: a program where there is no L1 support.

Given that black parents want their children to learn through the medium of English, the model that project researchers consider the fairest and with the greatest likelihood of success is the gradual transition model. They justify this choice by noting that this model would ensure close scrutiny of junior primary curriculum for coherence and continuity. There would be real gains by the teachers, who previously only had to cope with teaching English as a subject, but who would now use it for authentic consequences in the classroom, and thereby create long-term effective change in education through growth in their 
English competence. The traumatic experience of sudden changeover is obviated, effecting a probable decrease in the drop-out rate. This model is widely used in Anglophone Africa, and to the Threshold Project researchers, conditions seem appropriate for its introduction in South Africa.

One of the concerns with this model is that there is no substantial research evidence of success with this policy, although current research indicates this would be more effective than the present one. Another is the current major constraint of the junior primary teachers' relative lack of competence in English.

Researchers are well aware of the skepticism and hostility that educators will meet on the topic of educational reform due to the history of language policy. Previous reform proposals were based on language politics and other political considerations to the detriment of black education, so new reforms are bound to be viewed with skepticism. Project researchers support the consultation of the people affected by language policy, and believe that decisions should be made on the basis of informed awareness as much as possible. They concede that one model will not suffice in all school situations, and that language policy should allow for multiple models.

In conclusion, the researchers noted that it was not their purpose to come up with prescriptions but to increase community awareness of the central issues, thereby stimulating the questioning of policies and practices. "We have in mind to raise to public awareness and debate the need for formulating a language policy that meets the needs of the child while still accommodating the political aspirations of the broader community" (Macdonald, 1990a, p. 18). 


\section{Teacher Survey}

Teacher perceptions and experience will influence formulation and implementation of language policy. Although the aim of the survey conducted in September, 1993, was to get a preliminary picture of the teaching and learning of English in various South African contexts to inform curriculum planning, the teachers' answers are useful in gauging attitudes and experience as they might affect language policy. The report, conducted by the Core Syllabus Committee for English, is entitled "An Investigation into the Teaching and Learning of English in Primary and Secondary Schools in South Africa in 1993" and provides the reader with a glimpse of the multilingual nature of South African schools.

The questionnaires were distributed to English teachers in schools across the country. Of the 621 teachers who responded ( $40 \%$ of the total sample), $60 \%$ of the teachers were in contexts such as former DET and ex-homeland schools where English is the mother tongue of neither the teachers nor students. Generally, respondents were senior teachers with ten or more years of experience teaching with qualifications from colleges of education and some university courses. These respondents, according to the survey, are likely to be players in language policy and practice within their local school districts.

With regard to their home languages, respondents reflect the multicultural reality of the South African classroom. Although $40 \%$ of primary and $32 \%$ of high school teachers speak English as their home language, they reported twenty home languages spoken among this group. As to the students, $78 \%$ speak home languages other than English. The $22 \%$ who are English (L1) speakers is a higher percentage than average due to a high survey return from previously white schools. Forty-four per cent of primary teachers 
and $62 \%$ of high school teacher respondents reported that $76-100 \%$ of their students had a home language other than English.

Researchers found the most striking feature of the data was "the sheer multiplicity of languages in use at home and school. The minority of students learning English are in fact first language speakers of English, and yet the current medium of instruction policy demands first language competence from all learners" (emphasis theirs) (p.11). Also, the teachers expected to teach students to acquire English L1 competence are, for the most part, not L1 speakers of English.

Many of the questions in the 1993 survey concerned teaching methodologies and syllabus issues. Here I include only responses to those questions which dealt directly with language policy and medium of instruction. I also include the respondents' comments in the survey, as they illustrate the teachers' perceptions about the nature and direction of English teaching. Where implementation of a language policy would directly affect them if a change is made from present general practice of English as medium from Standard 3 on, percentages and choices vary between high school and primary teachers. (See Figure 2 for a graph representation of the following findings.)

When asked to choose between four different medium of instruction options, primary school teacher respondents $(\mathrm{N}=278)$ chose the following: $71 \%$ thought that English should be the medium from Class (grade) 1. $14 \%$ thought that the medium should be the mother tongue in all phases. $9 \%$ favored a gradual transition to English by the end of Standard 5 . $6 \%$ chose English as the medium from Standard 3 on. Comments selected by the survey committee are the following: 
English from pre-school. Young children learn new languages easily.

As English is considered a universal language, the child should be exposed to it as soon as he or she commences schooling.

Most of our pupils will never learn English or speak it frequently, because of the environment they live in.

Children should be taught in their mother-tongue. English can be taught as a subject in order to communicate, but not as medium of instruction.

English should be introduced at an early stage, because if children start using it at a later stage, then they tend to lack confidence, and as a result are not free to use the language.

High school teachers concurred with primary teachers for the first choice of medium of instruction options: $61 \%$ favored English from Class (grade) $1 ; 17 \%$ favored a gradual transition to English by the end of Standard 5; $12 \%$ chose English as medium from Standard 3 on; $10 \%$ answered that the mother tongue should be the medium in all phases.

Comments selected by surveyors are the following:

Gradual transition is less traumatic. Teacher training is required.

Policy should be differentiated on a regional or other basis tailored to the needs of different school communities.

English should not be forced on anyone, or be made into the "language of the oppressor", so: English gradually introduced into all phases, while mothertongue tuition takes place until a sufficient level of sophistication and desire for English has developed.

Children should continue to respect their mother-tongue as a language whilst gradually being introduced to the foreign medium.

I believe that learners must be taught the 'magic' of English at an early stage.

Figure 2. Teacher Preference for Medium of Instruction 
Figure 2. Teacher Preference for Medium of Instruction

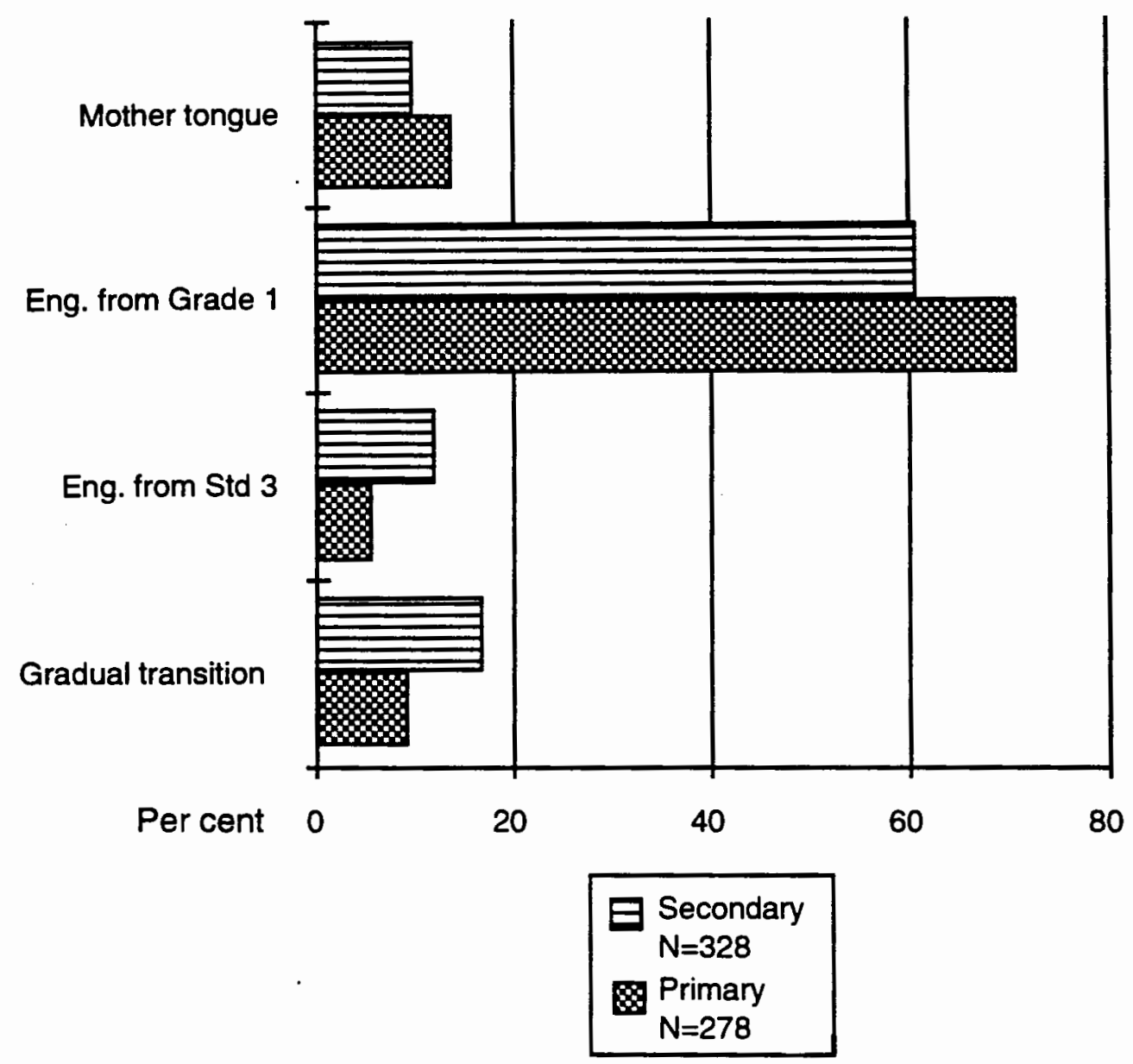

Source: Core Syllabus Committee for English, 1993 
The English teacher must be a competent English teacher.

English is an international language and the skills of English communication should be developed early.

\section{ARGUMENTS FAVORING AND OPPOSING ENGLISH AS MEDIUM OF INSTRUCTION}

Schmied (1991) observes that in Anglophone African countries the stronger the position of English, the earlier and deeper its impact on school children. There are generally four approaches to the teaching of English: 1) the straight-for-English approach, where students begin school learning all their subjects in English. This happens most often in linguistically heterogeneous areas, where they cannot agree on which African language to use or where parents see English as a means to socio-economic advancement, 2) English-asa-subject, in lower primary grades with a changeover between Standard 4-6 (grades 6-8) to English as medium of instruction. This has an advantage of allowing students to gain some level of competence in English before being burdened by learning content subjects through it. This approach is most favored by African countries today (Schmied, 1991), and practiced generally in Nigeria, Ghana, Uganda, Malawi, Zimbabwe, Botswana, Lesotho, Swaziland and South Africa, 3) using the local African language throughout primary education, if sufficiently developed and government supported, especially the national language(s), such as in Tanzania, Somalia, Ethiopia and Southern Sudan. English is an important subject, however, because it is usually the medium of instruction in all or some secondary schools. 4) English as a language for wider communication, where English is intensively taught as a subject in secondary 
school but instruction takes place in other languages such as Swahili, Arabic, French and Portuguese.

It is the medium of instruction that causes the hottest debates around language in education policy. Following are the four arguments most often put forward favoring and opposing English as the medium of instruction (Schmied, 1991). None of these arguments is adequately backed up by research and all can be refuted by the other side. Also, none of them is conclusive since studies could not control certain variables, such as parents' use of English, or much more favorable learning conditions in terms of many more schoolbooks and dedicated teachers. Nevertheless, these arguments set out the opinions and attitudes of both those who will set policy and those who will be affected by policy and may, therefore, determine through their acceptance, or lack thereof, whether the policy succeeds or not.

Arguments for English as medium of instruction (and their counter arguments) 1. A change to another language as medium of instruction will be enormously expensive. Opponents say that educational change will come anyway, so why not change the language together with the content?

2. The selection of an African language would threaten national unity, a goal of nation-building, and English is the only ethnically neutral language. Opponents concede this is a strong argument but argue it does not exclude the use of an African lingua franca.

3. It would be a large and costly effort to expand the vocabulary of African languages to meet the demands of science and technology. The critics of this view who advocate modernization of African languages point to Swahili as an example of speedy acquisition of a technical and scientific vocabulary. 
4. English has a unique status as the language of international communication, and it would be foolish not to take advantage of this. Critics argue this is not an argument for using English as medium of instruction but rather for teaching English, i.e. an EIL (English as an International Language) argument rather than an ESL argument.

Arguments for an African language as Medium of Instruction (and their counter arguments):

1. Psycholinguistic studies have shown that mother-tongue education is better for a child's cognitive development. However, other studies show multilingual education triggers otherwise latent mental capacities. Then again, English is not harmful provided that early education, possibly including literacy, has been carried out in the mother tongue.

2. English creates an elite class because native speakers of English have an unfair advantage. Critics of this position see English as a stepping stone to well-paid employment and favor its use and expansion as the medium of instruction. This view is based on the assumption that one gains greater competency in English if it is the medium of instruction. Those who do not believe this assumption to be necessarily true counter that the stepping-stone argument really speaks to the efficient teaching of English as a subject rather than its use as the medium of instruction.

3. It is time for African countries to shed the remnants of colonialism. Opponents argue that the English language today is no longer the property of one or two imperialistic nations.

4. English cannot carry the connotations and associations of an African identity, thereby alienating the African child from his or her cultural background. 
This is countered by examples of African writers conveying African life and culture in English. Also, African cultures incorporate many other features of Western culture, English being only one of them.

\section{THE ROLE OF ENGLISH IN OTHER AFRICAN EDUCATIONAL SYSTEMS}

The position of English in a nation-state depends on the language policy of the ruling government, which sees the educational sector as the most important place to apply the policy (Schmied, 1991). In this regard, English teaching in schools both reflects and shapes the national sociolinguistic situation.

Both Christian missionaries and colonial governments were suppliers of Western-style education. Curricula were based for the most part on the overseas models and reflected little in the way of African content. The administration of modern educational systems in Africa was dominated by expatriates as was teaching beyond the primary level (World Bank, 1988).

In the 1960's, when many African countries attained independence, governments adopted policies narrowly focused on the selection and function of the official language. This was usually English or French, the language of the former colonial power, adopted in the belief that it would serve important goals such as political integration and advancement of national unity. However, African societies remained multilingual with no reduction in the use of indigenous languages in the local communities, at home or in informal business relations. According to Langhan (1991, in Luckett, 1993), 41 of 45 post-colonial subSaharan African countries initially adopted language policies in which the excolonial language was the target medium of instruction in education. The results have been uniformly dismal. As a result, 37 out of 47 African countries 
that initially adopted second language medium of instruction policies are now reconsidering the use of first language medium of instruction policies (Poth, 1990, in Luckett, 1993).

An example of a link between language policies and national situations can be seen in the cases of Kenya and Tanzania. Both inherited similar systems of education with their independence from Britain in the early 1960's. Both countries had a school system using Swahili as the mother tongue medium for early or all primary education, followed by English as medium of instruction. They outlawed racial segregation and issued their first national development plans including new educational goals. Both countries initially considered increased economic output as a primary goal and eventual mass education as a second goal (Zuengler, 1985).

By 1969, Kenya and Tanzania issued their second development plans and their educational development goals began to diverge. Kenya continued to give priority to meeting manpower needs which necessitated that schools produce workers with skills and knowledge sufficient to support high economic growth. They chose not to change their educational language policy of English as medium of instruction.

In Tanzania, however, President Nyerere argued for an educational system that was no longer geared to the minority. He wanted each level of education to be complete in itself. Policy makers saw two problems that needed addressing; first, secondary students facing a new medium of instruction had to have intensive remedial instruction in English and second, there became a linguistic gap between the masses and those continuing on to higher education. There was concern that this alienation between the educated minority and the masses would undermine the goals of socialism and rural 
development. As a result, educational language policy was changed to retain Swahili as medium of instruction with English taking a secondary role.

Tanzania's successful language policy is not due solely to its link to the political goal of socialism. There were a number of important social factors that came together to support the success of the policy of Swahili as medium of instruction, such as Swahili's centuries-long tradition as a lingua franca and its use as medium of instruction by missionaries and Germans with attendant positive attitudes. Also, as a Bantu language, which is in the same family as most of the more than 130 languages spoken, it was not the native language of any one dominant group.

Compared to other African countries, South Africa's past divide and rule policies have actually institutionalized African languages far more than in most sub-Saharan countries (Gough, 1994). South Africa boasts a wide range of radio and television programs and African language newspapers and is probably one of the few countries in which official documents are printed in African languages, which is partially the result of the Bantustan system. Many African languages are compulsory subjects to matric level (graduation), which is unparalleled in other countries. Although past policies led to the neglect of African languages, compared to other African countries, South Africa is in the enviable position to build on and re-orient its multilingual structures.

\section{1 st World Congress of African Linguistics}

The National Language Project (NLP), based in Cape Town, was created in 1988 as a progressive, community-based organization. One of its areas of focus is to stimulate debate on language planning. At the 1st World Congress of African Linguistics in 1994, attended by at least fourteen African countries 
including South Africa, the NLP facilitated a workshop on democracy and language planning. Participants agreed on the following elements that should be embodied in a democratic approach to language planning (Crawhall, 1994):

- there need to be bodies concerned with promoting the use of African languages;

- language planning should be based on the principle of access to resources, achieving access through dominant/colonial languages, national languages or through both;

- empowerment through indigenous languages is important, but so is access to powerful and dominant languages;

- bi- or multilingualism should be a goal for all citizens;

- there needs to be a mixture (balance) of top-down and bottom-up planning; - lobbyists on language issues should be realistic about the political, economic and linguistic environments in their country; and

- the notion that multiculturalism will work against national unity must be challenged. The use of a single colonial language can also cause social and political divisions by favoring the educated elite over the majority.

Given the complexity of the issue, the workshop was unable to come up with a plan of action. Some felt that academic linguists were not the right people to drive this kind of initiative, though there were important roles for them to play in the debate.

\section{The Organization of African Unity}

The Organization of African Unity (OAU) provides a frame of reference to guide member states as to the manner in which they should approach handling the linguistic resources in their country. These guidelines are published 
in three documents: the OAU Charter and Rules of Procedure (1981), the Cultural Charter for Africa (1976), and The Language Plan of Action for Africa (1986).

The OAU clearly supports the adoption and practical promotion of African languages as official languages of the state and the formulation, with a minimum of delay, of a language policy that places an indigenous African language or languages spoken and in active use by its people at the center of its socio-economic development. It supports as well the establishment of a national language council, legal provision and practical promotion of African languages in official communication, and encouragement of the increased use of African languages as "vehicles of instruction at all educational levels" (Kashoki, 1994, p. 292).

A frustrated Zimbabwean wrote an impassioned article in the Harare Sunday Gazette (Chinyakata, 1994) decrying the forced use of English in his country. He pointed out that a "shocking" list of members of parliament had never opened their mouths in the chambers for fourteen years, so uncomfortable were they with using English, leaving the writer to conclude that half the population was not represented. He noted that thousands of educated people were denied career opportunities because the employer believed that English fluency was "a qualification to life itself." He looked at the school pass rate and saw "tremendous talent going down the drain" due to forced use of a non-native language. The writer is not alone in recognizing the disadvantages of the replacement of indigenous languages by English, the language of high status, and of international communication. Countries which chose English as their official language at independence are beginning to rethink their policies. 
A similar commentary is provided by Professor Mubanga Kashoki (1994) of the Institute for African Studies at the University of Zambia when he assessed Zambia's history and language policies, pointing out the following:

The language policy adopted in 1965 in Zambia served at once to deny the Zambian child this learning environment [where formerly students learned the fundamentals in the mother tongue], providing indeed a social recipe for rendering the child an illiterate frontline soldier in the cause of his own language, particularly in its written form. Cultural alienation follows. The child can no longer be expected to care for, respect or creatively use the language of his own mother and father (p. 290).

Furthermore, he adds, the rich literary traditions and accomplishments of the Zambian people in their indigenous languages are not being pursued by current writers, nor is there a sustained commitment to promoting a new literature in African languages. Professor Kashoki concludes by pointing out,

the most notable battle lost on Zambia's frontline has been its failure to summon the national will and political resolution necessary to induce its nation and provide the environment in which a comprehensive language policy can be drawn up-- one appropriately attuned to the country's long-term national and international interests (p. 291).

South Africa included a language policy in its constitution to make principled statements about the language rights of all its people. How it implements these broad policy statements, how much experimentation it allows, and to what degree its language policy correlates with other social and educational factors and with the desires of the people it affects, will determine whether it goes the way of its neighbors or travels a different road. 


\section{SUMMARY}

Because language issues, sometimes referred to as language problems, are embedded in social relations and society's institutions, they are complex by their very nature. Language issues take shape over time with respect to the national situation of a particular country. In South Africa, developing a language in education policy on the micro level that meets the needs and aspirations of all its citizens and, at the same time, on a macro level advances national goals is a daunting undertaking. Recognizing that past language policies have badly served Africans, the new government of South Africa has determined it must change these policies to help the country accomplish one of its most important national goals, that of redressing past inequities, thereby bringing the majority of its citizens into full participation in civic life.

ANC policy makers and education researchers laid the groundwork for policy discussion and debate in the early 1990's. Resources for policy analysis include a growing body of language policy and planning literature, some South African surveys and research, though limited, and experiences of other countries with language policy, particularly African countries.

In this chapter, I have highlighted some of these significant resources to help the reader view South African language policy development through the lens of various perspectives, underlying theoretical frameworks, and the country's historical past. The reader can use the information provided here as a foundation for understanding the direction South African policy makers are taking. This direction is described in the findings and discussion in Chapters IV and $V$. The next chapter describes the methodology I used in conducting my research. 


\section{CHAPTER III}

\section{METHODOLOGY}

This is a case study of how the 'new South Africa' is addressing the issue of language in education on a policy level. As I began my research about education in South Africa in preparation for writing a Fulbright-Hays grant proposal, I learned about the enormous impact not only of apartheid policies on education but also the accompanying language policies. I also learned that language policy was addressed in the 1993 Constitution to conform with new democratic principles and that discussion and debate would continue. The educational consequences of this country's language policy, which had negatively affected so many children over at least the last four decades, convinced me this was a topic of significant importance.

As Hartshorne (1995) noted, "When it is linked to colour prejudice or class privilege, for example, language becomes a highly emotional and political issue, capable of being mobilised as a powerful social instrument" (p.306). The Soweto Uprising of 1976, which began over the imposition of Afrikaans as a medium of instruction in math and science, is often cited as an illustration of Hartshorne's point. As language has been highly politicized in South Africa and tied to the control of ethnic cultures by the former white governments, language policies inevitably affected how Africans view their languages, their cultures, and their future. As South Africa works towards political, social and economic transformation, language policy continues to be debated and to take 
shape over time. A language in education policy is central to any educational reform.

I began my research upon learning of the award of the Fulbright grant six months before my group's departure. Initial research included two South African books, several articles and books on language policy, and the Macdonald research. After this initial research, I recognized that I would need to gather as much information in and from South Africa as possible and define the scope of the topic before deciding how to limit my research.

$I$ informed our host directors in Johannesburg and Pietermaritzburg of my interest in this topic, who then asked several speakers to address this topic as part of their presentations on education. One host, who teaches ESL at the University of Natal, gathered a number of articles for me as well as arranged a school interview and observations for me. Other school visitations were already on the group's itinerary.

Once in South Africa, I realized that the most important part of building the foundation of the research was to learn from everyone I met and everything I saw. Our itinerary was quite full, and I found little time for other research outside of planned school visits. When opportunities arose that I could take advantage of, I did. For example, I met with an educational publisher, attended a workshop by the Read Educational Trust and a communicative language teaching workshop at a teachers college that hosted our group.

I determined my findings would be composed of data collection from two sources: firsthand interviews and school visits, and articles and documents written by South Africans and other southern Africans who were contributing directly to the topic of language policy making in South Africa. My six-week 
visit to approximately twenty schools and three colleges provided valuable context for the readings.

\section{DATA COLLECTION}

After an initial review of materials available in the United States, 1 recognized that most of the pertinent articles would be located in South African publications, many of which were not readily available in the United States. While I was able to gather a few articles from two professors during my visit, the group's itinerary and my responsibilities did not allow time for library searches. Therefore, the bulk of articles from professional journals, educational publications, and newspapers was collected expressly for me by Colyn Davies of Vista University and Alice Goodwin-Davies of University of South Africa (UNISA), who had made presentations to our visiting group of teachers.

Reading articles and their references, I was able to identify those who were frequent contributors to the policy discussion. I began to network by first contacting a key policy researcher, the Director of the National Language Project (NLP) and frequent contributor of articles and research on language policy, Nigel Crawhall. He recommended certain references and sent me a publication and several issues of Bua!, the magazine published by NLP. Through Crawhall's recommendation, I obtained a recently published book directly from a publisher in South Africa. I wrote to another contributor to the discussion of language policy, Kathy Luckett of the University of Natal, who sent on other material. Peter Plüddemann of PRAESA (Project for the Study of Alternative Education in South Africa) was a recommended source who responded to my fax with information and a bibliography of language policy articles. Each one 
made a recommendation of resources that would lead to my next acquisition of information.

Because it was neither possible nor necessary to identify and collect every article or document being written about the topic, I determined I would base my case study on representative documents and articles. I tried to make sure I acquired the literature recommended to me by people working in the policy area as well as articles often cited by various writers. About three months after my visit, the ANC-led government produced a major discussion document on this topic (ANC, 1995) and later the 1996 Constitution was passed by Parliament. Official movement had taken place, yet there was more language planning to come.

\section{PROCEDURES}

\section{Data}

After reading dozens of articles and several books, I found my interest clearly lay in the how, why and who of developing language policy and the problematic issue of medium of instruction in primary and secondary schools. Synthesis of the collected materials included a determination of the relevance of each article and what information should be conveyed to make a coherent picture of post-apartheid policy discussions. Retaining a manageable focus in this study necessitated restricting the exploration of language issues to those named in the guiding questions. Other issues named in "Limitations of the Study" in Chapter 1 had to be set aside from this study. 


\section{Interviews}

The opportunity to interview principals, teachers and others involved in education presented itself frequently during the three weeks in which our group visited schools. I requested interviews when principals greeted us and made themselves available. Teachers usually did not have time to break away from their responsibilities and did not often approach me. I followed a similar line of questions for each interview, but variations in school visitations and situations sometimes changed the direction of the discussion. Note taking accompanied interview questions. Principals welcomed my interest in their school and were forthcoming in answering my questions. In most of the predominantly white schools, our group was addressed by one or more administrators in a presentation, followed by a question and answer period. These were often followed by tea and refreshments, a time when we could talk informally to administrators and some teachers.

Interview questions generally aimed at determining the community and language background(s) of the students in the school I was visiting, and what languages were offered and used as medium(s) of instruction. I asked the principal's opinion about the present language policy, how it was working, and about parent support for education generally and how they felt about English. If there was time, I often asked them to speculate on what changes might be made in the future, how they would be made, and what changes the principal would like to see take place. 


\section{Observations}

School visits were arranged by our host directors so that group members could sit in and watch, and sometimes participate in, classes from junior primary to matric level. Situations ranged from student presentations such as dancing and singing to regular class work, with no introductions or reference made about our presence in the classroom. Sometimes I took notes during class if I felt I did not appear as an evaluator, otherwise, I would make notes immediately following the visit. In black schools, where English was not the home language, materials were so bare that there were few examples of texts, handouts, exams or syllabi to look at.

\section{School Environments}

I visited schools that ranged from those with many resources to those with hardly any. The predominantly white schools were similar to most American schools in look and feel. To describe the black schools I visited, I offer the following quote as a helpful method of conceptualizing the environment:

..take whatever comes to mind as a 'normal' school, then, by a process of mental subtraction, take away most (or all) of its constituents: take away electricity, adequate plumbing, solid and weather-proof buildings; take away libraries and resource centres, video and audio facilities; take away well-trained teachers and competent managerial staff; take away sufficient chairs and tables (or desks), sufficient space for pupils and teachers to move around within a classroom; take away textbooks (whether appropriate or not); take away appropriate and readily available syllabuses; take away parental support (both material and moral or psychological), etc. What you are left with is probably much closer to the norm for the majority of black South African pupils. (Walters, 1996, p. 210)

In Chapter IV, I include descriptions of my firsthand experiences visiting South African schools. Rather than a chronological or random listing of schools 
visited, I grouped them from predominantly white schools to all black schools to illustrate the wide disparity of resources. The number and duration of my school visits were not statistically significant to form valid propositions and are anecdotal in nature. 


\section{CHAPTERIV}

\section{FINDINGS}

This chapter will present data from my research in three sections. The first is the personal account of my interviews and observations in South African schools. The second is a presentation of language policy discussions and positions taken from articles and documents that I obtained from South Africa. The third is a presentation of three proposed models that seek to ensure the implementation of nascent language in education policies. The findings are limited to the guiding questions of this study, even though other important issues are addressed in the articles and documents, such as those mentioned in Limitations of the Study in Chapter 1.

\section{SCHOOL VISITS}

During July and August, 1995, I visited approximately twenty schools in urban and rural areas in the KwaZulu/Natal and E. Transvaal regions and one school outside Cape Town. Descriptions of sixteen of these visits include information based on school interviews, presentations by school staff and personal observations. The descriptions are arranged here from predominately white schools to all black schools. The school environments are compared in Chapter V.

The purpose of the visits and interviews was to learn more about the culture as it was expressed in the education system. Descriptions of the school 
environments in this chapter present my overall impression of what each school was able to provide its students but are limited to what I was able to observe at that given time and to what was shared with me by principals and teachers. All the principals I met were sincere in their welcome to their school. All admitted shortcomings in what they were trying to accomplish. Principals of the poorest schools were frank about the problems they faced. Further, these descriptions are intended to give a human face to the more abstract and statistical look at the South African education system found in academic articles and language policy discussion documents. A map is provided to indicate the areas of my visit (see Figure 3).

\section{A. Maritzburg College - presentation and observation}

Founded in 1863, Maritzburg College is one of the oldest high schools in the KwaZulu/Natal province. It is very much in the English public school model with emphasis on strict discipline. It is now predominantly English-speaking but was formerly an Afrikaans-medium school. It has been a Model C school since 1992, which means that as a formerly all-white school it must now accept students of all races to continue to receive state funding. In 1995, ten percent of its 1066 male student body, age 13-18 years old, were non-white and this percentage is increasing. The youngest grade, Standard 6 (grade 8 ), had twenty per cent non-white students. School fees were R3000 per year (in 1995,3000 rands $=\$ 833$ ), with the student body socio-economically above the norm.

Students are admitted on merit. Administrators said there was a continuing question on how to rate applicants from black and Indian schools. 
Figure 3. Map of South Africa indicating areas of schools visited.

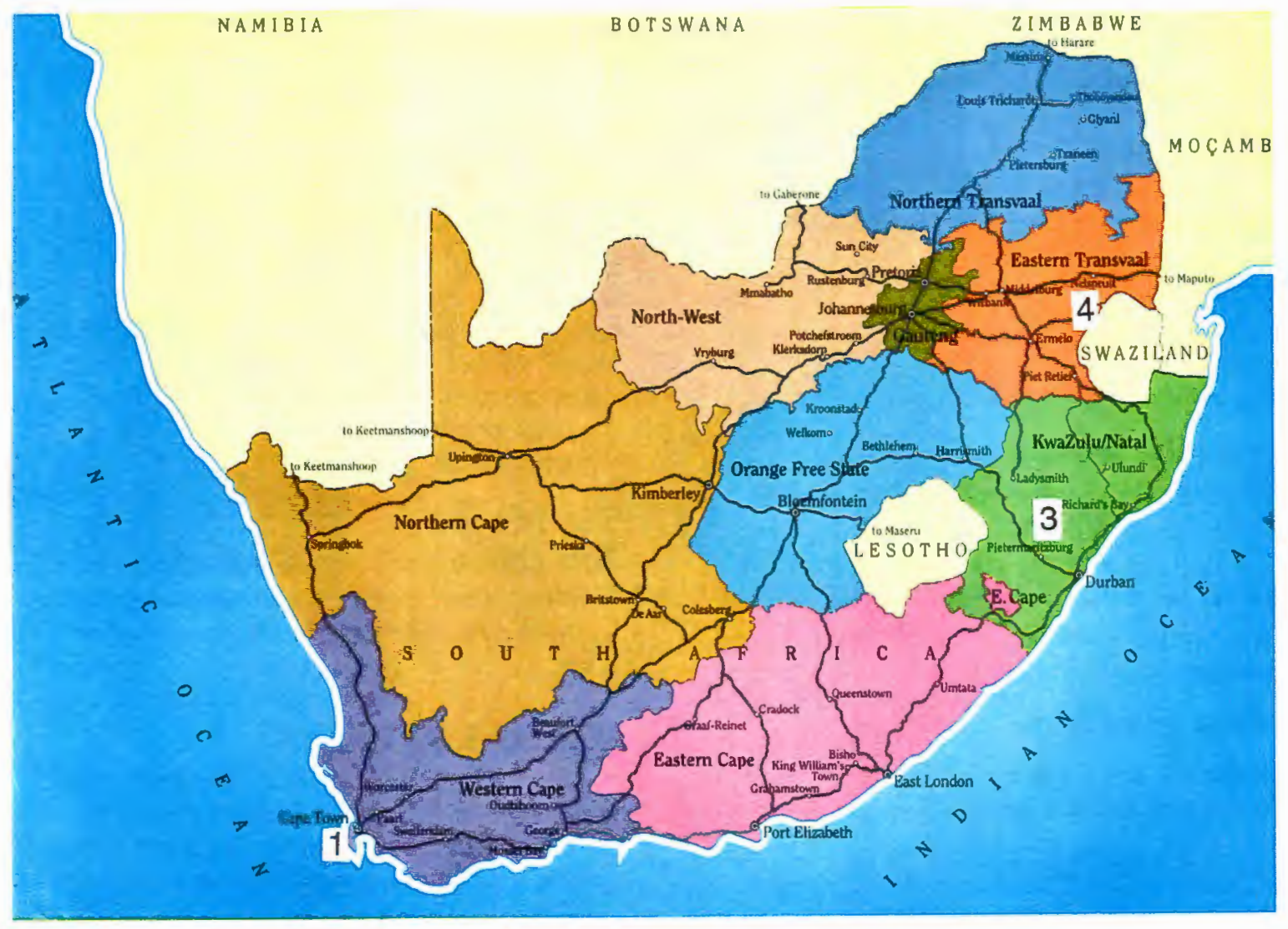

Area 1: Western Cape: Robben Island, off the coast of Cape Town Area 2: KwaZulu/Natal: Pietermaritzburg

Area 3: KwaZulu/Natal: Rural schools east of Pietermaritzburg Area 4: Eastern Transvaal: Nelspruit and vicinity 
The school's admission criteria included an entrance test, confidential school reports and an IQ test. During the first couple years of integration, the school was fairly dogmatic about admission based on a chosen standard of measure of academic ability. School staff did recognize that their tests were whiteoriented. and have tried to eliminate racially-biased questions. In the two years prior to 1995, they had become much more flexible. The Standard 4 syllabus provided the entrance test for entering Standard 6 students from black and Indian schools. In 1995, they were accepting a lower academic standard and putting in academic support mechanisms at the school's expense.

The funding for staff salaries came from the central government, but the school funded additional personnel. The governance of the school showed a great deal of parental involvement. There was a Governing Body of 14 and one ex officio member, eight elected by the parents and six by the Trust. The Trust looked at the skills of the parent members and filled in the gaps, so business, accounting, law and similar professional skills were present. The Governing Body appointed and hired all the staff, including the principal. It met four times a year and eight times in sub-committees.

The heads of departments looked after the academic and psychological needs of the students. The subject heads oversaw the academic policy in the school. The presenting administrator noted there was not much freedom in what and how teachers taught their subjects compared to other countries. The teacher was very much in charge of the classroom, still using old fashioned teaching methods. The matric exam (taken at the end of secondary school) dominated everything. There was not much time to go outside the curriculum, as students had to pass four of six exams at higher standard level. Asked what changes he saw for the future, the administrator thought there would be 
a more flexible exit system, with students being able to leave school at different times for other educational and training opportunities. The present matric exam provided school leavers with a diploma for those who passed it, as well as identified top achievers and those students who qualified for university admission. For one exam to attempt to satisfy multiple objectives was considered educationally questionable.

Compulsory languages taught at Maritzburg College were English and Afrikaans from Forms 2-6 (grades 8-12) with Zulu compulsory in grade 8 and optional for grades 9-12.

I observed an English class that was attended by about twenty young men, around 17 years old. The teacher, who had taught at Maritzburg College for many years, conducted her class in a relaxed and supportive style. The class reviewed the reading that had been assigned. The teacher asked questions and called for voluntary responses and at times called on individual students. The students seemed engaged, relaxed and respectful of the teacher and each other. The classroom was fairly spartan in appearance without the colorful bulletin boards and various resources generally found in American classrooms, but every student had his own desk, chair and book.

A tour of the school revealed beautifully landscaped grounds, courtyards, a feeling of school tradition and discipline, facilities and grounds for a wide range of fifteen different sports, in which participation was required, and somewhat bare, but adequate quarters for the third of the student body who were boarders. As we passed through hallways, students greeted us. Even in the few hours we spent at the school, the other American teachers and I felt a strong sense of high expectations for excellence, self-discipline, achievement, participation in activities and sport, and honor of tradition. 
B. Lowveld High School - host school

Our group were guests of this English-speaking high school during our week-long stay in E. Transvaal. The school owned two guest houses which housed many of us for a minimal sum. Another teacher and I were extra, so we stayed in the infirmary and took our breakfasts at the school cafeteria with boarding students. The school was built in 1970 and, in 1991, became a Model C school, accepting students of all race groups.

The school was large, with many buildings and sport fields. As the state paid teachers' salaries, the rest of the school was managed and financed by a Governing Body, a democratically elected group of parents who assisted the school administrators. Parent evenings were regularly planned to further communication between parents and teachers. They had a media center as well as a computer center that could accommodate thirty students. Lowveld is co-educational, and girls also participate in sports and extracurricular activities just as the boys do. They had eleven sports offered as well as clubs, school plays and operettas. There were 360 boarders, equally divided between boys and girls.

The academic offerings covered the usual high school subjects as well as Bible Education. The two languages offered, English and Afrikaans, were compulsory. They did offer some bridging classes to help with language.

\section{Nelspruit Hoërschool - presentation and observation}

Nelspruit Hoërschool, located in the same city as Lowveld High School above, is an Afrikaans-medium high school, teaching Standard 6-10 (grades 812), with forty-two teachers and 1,050 students (ratio 1:25). It is a statesubsidized 'Model C' school that became multi-racial in 1995. It had a 
governing board and sought an active parent community. Many of the facilities were paid for and arranged by parents. The fees were R1845/year $(=\$ 513)$. The careers of the parents were diverse, ranging from farming to business and the professions.

The ideological foundation of the school was to maintain Christian norms, to practice Afrikaans without a disparagement of other languages, and to acknowledge authority and the belief that strong discipline leads to selfdiscipline. There were no political activities allowed. Corporal punishment had just been banned in the province two weeks before our August, 1995 visit. Social activities were planned by prefects, who were students chosen by equal vote of previous prefects, teachers and students. Classes were conducted in Afrikaans, and everyone studied English as L2 in every grade. We saw two examples of vocational education where students learned from hands-on education. As the region is growing, the school made the decision to convert its home economics facilities to support a new hotel/restaurant course, at the cost of about $\$ 56,000$. It would become a private enterprise for student management. An agriculture class had adjacent land for students to grow crops. Seventy percent of the students went on to post-secondary education. In a brief conversation with the English teacher, I learned that her English classes averaged forty students per class. She used the communicative approach, but the syllabus was so wide and long in the matric level that she didn't have any latitude in what she taught. Texts had to be read in class and not at home due to the limited number of English texts available. I asked about teaching English in black schools in the area. She answered that there was "a bit of a backlash due to the disparity in teacher preparation and resource allocation, and the black schools didn't want white teachers." 
Our group met for about fifteen minutes with chosen students for morning coffee and refreshments. The students I spoke with, probably selected from the best and brightest of the school, seemed very excited to be there, were very happy at their school, spoke excellent English, and were interested in learning about American teenagers. We discussed music and high school life.

D. Wartburg High School - interview with principal, observation

I interviewed the principal of Wartburg High School, a Model C school located in a German heritage farming area in the KwaZulu/Natal province. The formerly all-white school had 350 students, of which fewer than twenty were black. Even though the school is now open to other races, English was the medium of instruction, so students had to be competent in English to attend. The teachers were paid by the government at a 1:40 teacher-student ratio. The rest of the costs were borne by the students' families at the school fee of R2000/yr. (=\$720). They had an active parent group which had done significant fundraising in the last four years, buying three minivans, cricket and tennis equipment, and computers. The fees help supplement staffing funds from the government to bring down class size. Governing the school was a parent school board. They had annual general meetings where anyone could speak on any issue. In addition, there were parent evenings to enable communication between staff and parents.

The principal noted that while staff allocation was done by the government, black teachers didn't want to be at Wartburg. Educators were very aware of the discrepancies. There was some outreach to provide educational support to the black community, but invariably it was met with a strong silence. The school was advertising for a "bridging" teacher, who would 
be funded by the parents, to help non-native English students, but they had had a poor response.

As to curriculum and instruction, Standard 6-7 (grades 8-9) were fairly prescriptive course disciplines and were mainly self-contained. From Standard 8 on, there were forty "packages" to choose from. Students had a nine-period day with 35-minute classes. The principal reported there were quite different teaching styles within the school--direct instruction with little student initiation or participation, as well as a student-centered style. The syllabus allowed little teacher discretion due to the importance of the matric exam. One of the American teachers saw the same geography lesson here that he later saw taught in a different province.

The study of Afrikaans was still compulsory. All classes were taught in English. Most students studied or knew German due to the heritage of the community. Assemblies were held in rotating languages: English, Afrikaans and German.

The school atmosphere was very friendly and comfortable. A tour of the school revealed an environment similar to a typical American high school with outfitted classrooms, well maintained buildings, sports fields, and trophies in the entrance hall of the school.

\section{E. St. Charles College - presentation and observation}

This is a private school for boys in Pietermaritzburg, KwaZulu/Natal, that was founded in 1875 by a Catholic order. The school has a history of multicultural education typical of private schools. In the 1940's, the government took a dim view of Catholic schools who opposed them, so the government disallowed Catholic teachers in other countries from their order to 
come to South Africa. The order couldn't keep up the training and staffing among the brothers, so in 1979 they changed their staff to an ecumenical group. The government bought the grounds from the church, and the school's governing board rented it back from the government. For economic reasons the school has had to pare down its academic offerings. School fees covered eighty per cent of the cost of the school; the government grant of R200 (=\$72) per pupil funded the rest.

There was an active parent group. Mothers staffed a small school store, whose revenues went to school activities. The school still confronted the criticism of elitism in that they had to exclude some students by virtue of the cost, but the administrator called their community "unpretentious."

The racial composition had decreased from $40 \%$ to $35 \%$ non-white due to the opening up of Model C, previously all-white, schools. Scholarships had helped return some of these students to St. Charles College. They did have entrance exams, but they knew they were problematic due to cultural bias and assumption of English language-knowledge as well as the educationally-deprived backgrounds of many students. There was ESL help for non-native speakers. Students also went to their other teachers for help. The school administration believed that motivation is the key to making the grade.

A tour of the school revealed beautiful grounds, well-maintained buildings, a library, sport fields, dormitories for boarders, a chapel, cafeteria, teachers' lounge and meeting area. This said, the classrooms, library, and sport facilities had no more resources, and sometimes fewer, than one would expect to find at a typical American school. The cafeteria lunch was set by black female staff who wore uniforms including little stiff, white hats reminiscent of American antebellum days. 
The classroom atmosphere seemed relaxed but under control. There seemed to be mutual respect among the teachers and students. An ESL class I observed contained only seven students, four of whom were from Frenchspeaking Mauritius. The young teacher was supportive of student responses and presented a lesson in which students discussed a magazine article they had read. With her guidance, they discussed the ideas and content of the article, and also stopped to review certain vocabulary and idioms in the article.

\section{F. Robben Island Primary School - presentation and observation}

The Afrikaans-medium school of forty-three white students was located on Robben Island off the coast of Cape Town. Robben Island is the site of a prison renowned for incarcerating Nelson Mandela and other high profile political activists during the apartheid era. The only people living on the island were either in prison or worked at the prison. The children, then, were from families associated with running the prison. Visitors had to apply for permission to visit the island and submit their names and passport numbers several days ahead before being allowed to board the ferry to the island. We were accompanied on this visit by Ralph Hines of the U.S. Dept. of Education, who was visiting several Fulbright-Hays groups in Southern Africa, and Brian Heath, the regional director for Cape Town schools.

As this was our first school visit, Mr. Heath gave us an overview of some of the challenges facing school administrations across the country, such as the need for inservice training, the need for redistributing teachers and administrators from areas with oversupply to those undersupplied, the need for bridging classes and creative programs to help meet the needs of all children, often language-related needs, and balancing student-teacher ratios. 
The classrooms were enclosed in one building. Classrooms were tidy with children's artwork giving color to the room. Except for the standard uniforms, it reminded me of what American elementary schools looked like in the 1950's. Secondary ștudents went to boarding school, and if in Cape Town, they came back on weekends, as daily ferry service was too infrequent to accommodate school hours.

G. Penryn College - interview with principal and observation

The school was founded on the concept that a non-racial school in the Lowveld (in E. Transvaal) could be an advantage in a rural community by acting as a model school for the area, use English as its medium of instruction, provide academic content with technical and agricultural options, and employ top-class teachers. It was also intended to double as an outreach center and an adult education center. It has organized courses to upgrade teachers and to link urban St. Stithians College of Johannesburg in a lasting relationship that would allow ongoing inter-school staff liaison and sharing of expertise. Visits by the St. Stithians boys enables students to work together on biology, geography and ecological projects or enjoy recreation, such as hiking and soccer. The school, founded under the Methodist umbrella, would be approved by the community and feed its educated children back into the area for its general upliftment.

The principal of Penryn College in the E. Transvaal province has been with the school since it opened in 1990 as a $100 \%$ black school with English-speaking white teachers. The school began with pre-primary children, four to five years old, increasing a grade each year. Students in grade 1 had to be able to understand what the teacher was saying to be enrolled. 
The home language was primarily Swati, but there were also Tsonga, Zulu and Afrikaans speakers and one Filipino. The principal reported that parents were highly motivated, "because they realize that the key to their children's future in jobs rests with English," which is the language of government, business and commerce and any national organization. "The president speaks English to South Africans and the world, a powerful symbol." The principal said that parents expressed negative feeling towards Swati. The language is not developed or utilized for school (there were very few books published in Swati) and was only used for conversation, 'so what's the point?', they asked. A Swati teacher came in to do bridging classes, but only parttime. The Molteno Project develops appropriate materials and in-service teacher training to help teachers and students bridge to English. Penryn used their materials as well as a variety of methods to support the students, but bridging classes remain a "dilemma." The principal indicated that students did not want to continue their home language when they got to secondary school, because they wanted English for the future.

The school was managed by several groups. The Penryn Trust raised funds for capital development, and a fundraising committee met monthly at St. Stithians College in Johannesburg. The Penryn Council controlled everyday management of the school in consultation with the headmaster. It consisted of representatives of the parents, Trust, Methodist Church and community. The Penryn Parents Association had eight elected members.

The curriculum consisted of English, Afrikaans, Swati, maths and science, environmental studies (geography, history, biology), design and technology, computer studies, art, music, life skills, religious education and media education. 
There were thirteen sports offered, a swimming pool was under construction and there were cultural offerings such as choir, chess, wildlife and excursions.

I observed a Standard 4 English class. They were practicing summarizing material by determining what to underline in the text with teacher guidance. In a conversation after class, the teacher told me students were looking for credentials. He asks parents to chat with their children in Swati so they can learn something, then be able to transfer concepts when in school. When this teacher worked in a mission school teaching Grade 1, he said that he began to realize that mother tongue education and literacy in the mother tongue was "essential."

\section{H. St. Joseph Primary School - teacher interview}

We arrived at the end of the school day, just as students were doing the Friday cleaning. St. Joseph School is a recently built rural school in KwaZulu/Natal, with two classroom buildings, bare land surrounding the school, classrooms with new chairs, desks and chalkboard, but with few basic supplies. They had 260 Zulu students. Students gathered at a corner of the building to sing their national anthem for us, whose chorus is in three languages and sung in harmony.

I took the opportunity to interview one of our hosts who taught there. On the topic of language she reported that parents wanted their children to speak English, that to them to be educated meant to be able to speak English. She stated, "Nelson Mandela always speaks English." The Zulus there have retained their home language and the parents cannot speak English.

The medium of instruction was supposed to have been English from Standard 3, but the teacher said the "students in Standard 5 were totally 
thrown" in content classes. A neighboring school was even less able to cope with English. This teacher, who is white and had good teacher preparation, noted that teachers at her school needed to have further teacher preparation and education, which they were "keen to do." However, the teachers were often absent, and children were "often the last of their concerns."

For support the school used services of READ (the acronym stands for read, educate and develop), a non-governmental organization supporting education with books and teacher workshops. They did have a parent-teacher association, and the teacher indicated that "parents do try to make a difference."

1. Montebello Primary School - principal interview and observation

Montebello School is a rural, parochial school that was state-aided since 1993. It served six hundred Zulu children in Grade 1 to Standard 5, five hundred from the local community and about one hundred boarders, with fifteen teachers including the principal. The school was built in a familiar elementary school layout. Despite large classes where some classrooms were crowded, the children appeared engaged in their learning and cheerful. It was clear from our tour with the principal there was a great deal of affection between the principal and the students. During recess I saw one girl come from somewhere on the school field bringing a large plastic container of water labeled "Std 2," which she ably balanced on her head, taking it to her classroom. Dozens of others gathered around one teacher of our American group to participate in a repetition song with movements, thoroughly enjoying the new experience. 
In my interview with the principal concerning language, she said students studied English as a subject in the first four years, changing to English as medium of instruction in Standard 3. They also taught Afrikaans from Standard 1-5. The parents thought children should learn English, but the principal thinks it is still important to teach in Zulu, and that it was fine to use both languages in teaching. As to changes the principal would like to see, she said that she didn't want lectures, but rather to involve the students, using actions. They didn't have enough teaching aids and apparatus. When I asked how the changeover to English went, she said, "It's a struggle. You must drill them first. If they understand, they cannot answer. The parents haven't come to the stage of discussing language with the teachers. Only now the teachers will be involved with the new syllabus which will come from Pietermaritzburg" (the nearest big city).

J. Khwezi Junior Primary School - interview with principal; four observations Khwezi Junior Primary School is located in a poor area near Pietermaritzburg in KwaZulu/Natal. The school had about five hundred students with a 1:32 teacher-student ratio. Officially it should be 1:40, but parents were interested in their children learning English, so many had moved from Khwezi Primary School to Model C and Indian schools where they thought the students would receive better education in English. The principal said, "In this setting it is not conducive to learning English." Afrikaans was dropped in 1995. The children spoke Zulu and were from poorer families. School fees were R10 a year $(=\$ 3)$ which was used to buy cleaning materials and sports equipment. The school facilities were not bad, he reported, because they had been under the DET from Pretoria. They had food, toothbrushes and toothpaste there for the students. 
There was an elected governing body of nine parents. If there was a problem, the principal would report to them. Though there was some parental involvement, the home environment was part of the problem in providing education for the students. Most of the families were broken, and there was a lot of drug abuse. The principal said, "the parents are not responsible (toward their children)." That year (1995) they had children living on the street admitted to the school. There was a special provision for boarding them, and they were brought to school in a minibus. There was a problem with weekend vandalism.

When I asked about how well the students did with the switchover to English at Standard 3, the principal reported that about $60 \%$ of them were coping. Those that went to white schools did all right, depending on their family background. This school was the only one that I visited that had a copy of the new language syllabus.

I observed three English classes and one science class for about twenty minutes each. The Standard 3 class of thirty-four students was working on adjectives and their opposites. They worked on the chalkboard and in their individual composition books. There were lots of hands going up when asked to contribute words. Homework required them to copy a list from the board and write a list of opposites at home and have their parents sign their book. There were no reading or textbooks present in the room, only the students' composition books.

In Standard 5, thirty-nine students were working on putting active verbs into the passive. The teacher used repetition drills as well words such as "tense" and "helping verb." When the sentence offered by a student was correct, the teacher wrote it on the board. They also had homework for the 
next day. There were no books in the classroom except for some reading books supplied by READ, a non-governmental organization.

In the Standard 4 class of thirty-two students, the teacher and students discussed adverbs, what they do and what kinds of adverbs there are. They would use them in original sentences, identifying what kinds they were (time, place, manner, etc.). This class was very similar to the other two English classes in teaching style.

The science class (Standard 4), the second year of English-medium instruction, focused on studying the parts of a locust. The teacher had drawn on the back of a small poster the likeness of a locust with its anatomical parts named. He gave the entire lecture in English with only a little Zulu here and there. Because it was generally frowned on to use code switching (employing the mother tongue to support the target language) as a teaching strategy, I wasn't sure if my presence changed the delivery of the lesson. The teacher repeated words often so that students would be familiar with them, using intonation to indicate when students were to say the next word out loud or finish the target word he began with the first syllable. This method, called roterhythm, must have been used often, as the students understood the prompt well and joined in at the appropriate time every time. There were no books, no science teaching materials or aids except for the handmade drawing. The students did not have pencils or take notes. They sat attentively at their desks, listening and repeating throughout the entire lesson. The teacher said a future activity would be to collect a locust and work in groups of four with a worksheet. 
K. Crocodile Valley Primary School - principal interview and observation

This is a farm school on the property of a large citrus estate in the E. Transvaal. There were nine teachers including the principal and 359 students (1:40 ratio). The students came from families that work on the farm. They were mainly Swati speakers and a few Tsongas. The principal herself had Swati as a home language. She had been at the school since 1973 and became principal of both junior and senior primary schools in 1987. Families paid R7 ( $=\$ 2)$ in school fees, which went toward school materials.

Before 1990, English was begun as a subject in Grade 1, but the DET moved it to Grade 2, where it is now. Students changed to English as medium of instruction in Standard 3, however, Swati was taught all the way through in reading, writing, poems, and recitation. Their reading books were provided by the government. In order to help with comprehension of English, teachers used practical activities to help students understand what the words meant, as well as using teaching aids. The principal reported that there was a problem in Standard 3 when English became the medium of instruction, because students didn't have adequate preparation. Math and science had to be done in English. She said, "if we have a very good background in English, there won't be a problem to be moving on to a good job."

If the principal could make a change, it would be to introduce English in Grade 1. The Dept. of Education would decide and tell this school. They were still waiting for a syllabus. In 1993, the Dept. of Education sent a survey to the school about English. The principal asked the community what they thought, and they were very positive about English. They wanted to catch up with the English schools in town. They preferred English over Afrikaans, partly because it was the language of the owner of the farm. She said the 'coloured' and 
Indian neighboring schools were English-speaking. In primary school they had to do well in English and math to get into a good secondary school.

In response to my question about what were the most important factors for students to get a good education, the principal expressed a need for qualified teachers who knew what the student needed. "They need a conducive environment where the teachers can deliver what the child needs." The parents were unable to provide much. The homes were too small to have a place to study, because the bedroom, kitchen and dining room were all in one. The principal reported that the parents were not interested and saw no value in homework or reading.

Junior primary students went outside to sing several songs for our group in English. All of the songs had some physical action associated with the words, and they had a fun time singing for us. Other students dressed in traditional dress to do some drumming and dancing for us. During the morning break between classes, the children lined up with various-sized plastic containers, and a couple adults ladled some kind of soupy meal into them.

I observed Hazel's English class in Standard 5. She had the smallest number of students, 22, but said most were $40-50$ per class. Hazel's class was unique in that she did not follow the syllabus that day, perhaps because she anticipated our visit. She asked the students, "Who is the most important person in your life?" Students contributed answers like, "God, because He created me" and "Jesus." Hazel produced a mirror to show each student who was the most important. She asked, "Aren't you proud of yourself?" She played a cassette tape, "Hero" by Mariah Carey, and talked about its message. Groups of four students talked about it, and one from each group 
back to the class from a piece they wrote. There was appreciation for the responses, no correction of language or content, and applause.

Later, I asked the principal about Hazel, because her teaching style was so very different from anything I had seen in South Africa. She said that Hazel had attended an Indian teachers college in Johannesburg, which did a better job of preparing teachers. This farm school has used English Through Activity for many years, even though the DET came in and set up other syllabi. Hazel was very happy to have us visit and also let us visit her home, a short walk from the classroom. It was built in the typical round-style housing of black South Africans with a wall separating the small bedroom from the small kitchen and sitting room.

\section{Miele High School - observation}

This school was located in a very rural area of KwaZulu/Natal close to our host school, Applesbosch Teachers College. The students and teachers were all Zulus. Our American group of four were first greeted by the principal, whose office was quite small and bare of practically everything save a desk and chair. There were no books or shelves. An American teacher was sent to observe a class, but because there was no teacher present, he taught the class himself. I observed a Standard 10 (matric) class of twenty-five students who shared seats and desks. The English teacher, who lived next door to my hosts and whose English was flawless, explained a grammar point using the chalkboard and called on students for responses. There were no texts or reading books in the classroom. The teacher later explained that the class was small, because so many had dropped out of school by this age. When I 
observed that so many of the students looked older, he said many were 19 or 20 years old.

\section{Sikhulile High School - observation}

This school was in the same vicinity as the school described above. There were many broken windows and a corrugated iron roof. When I arrived, a student moved to give me her seat and wiped it off with her handkerchief. Most students had school bags. Next door there was a lot of talking, because the teacher was absent. In my classroom the teacher had just given an assignment for students to choose from magazine pictures she had cut out and write three to four paragraphs or a poem about the picture. She passed out a sticky substance so they could attach the picture to their composition books. They went to work quietly without asking any questions. The teacher did not interact with them while they worked. She called students forward to read their essays and poems. I was quite impressed with the quality of ideas representing the simple pictures they chose. There was real feeling expressed in the poems. At the end of the class I asked one student if I could copy her essay, because I enjoyed it so much, and she was happy to comply. I asked the small group of girls around my desk about learning English. They responded that they liked it, and it was good to be able to talk to people from other groups (though they are all of the same language group in this school).

N. Woodhouse Primary School - teacher interview and observation

Although the school was to have been notified of our visit, the principal was away and teachers seemed unaware we would be coming to observe their school. A teacher stepped in to accommodate us, arrange our class visits and answer our questions. Woodhouse was a farm school with 346 students and 
eight teachers including the principal. The students came mostly from families that worked on the citrus farm. Others lived with pensioners like grandparents. Most families did not have electricity.

There are a number of home languages, with Swati, Sotho and Tsonga being the most prominent. One hundred percent of the students came without exposure to English. The teacher said they needed a preschool, because students did not even know how to hold a book. Sometimes they had children who could cope, other times they had children coming hungry and the school must involve the social worker. They had no lunch program. They applied for it, but the teacher reported that three successive checks "were lost in the office in Nelspruit," which was not very responsive. He also indicated that parents did not have much interest in the childrens' education.

"The teachers come in early and are very dedicated. They have all attended teachers college." The teacher I interviewed reported that the female teachers were not improving their English in that they didn't seek reading material. Teachers needed further training in different subjects, but they didn't hear about opportunities without a telephone. They got their books from the state, but they didn't have teaching aids. There was a subject advisor that specialized in English, organizing courses to upgrade teachers' English and methodology. A team visited there once, but there was no follow up. The teacher said, "He keeps in contact once in a blue moon."

The class size was upper 30 's to 50 , so teachers couldn't give each student personal attention. English was introduced as a subject in Grade 2 and the next year Afrikaans was introduced. With the new curriculum to come in 1996, the school would be able to choose one language, which would probably be English. The extra period would be used for teaching science or math. Their 
school fees were R10 ( $(\$ 3)$ a year and paid for sports, which consisted of cross country, netball, volleyball, track. The students competed against other schools and had just started playing against white counterparts. "Now they can go to other primary schools (because of the sports) to learn about things. It is a great change."

I visited a Grade 2 class in English with fifty students. The teacher taught the prepositions "in front of, "next to" and "behind" by having students come up in front of the class, be placed next to each other, and so on, and the class was then prompted to make a short sentence describing the arrangement. Sitting at the teacher's desk, I noticed a very small paperback book open on her desk that had language lessons listed, and I found this particular one. There were no directions on how to teach it, just the listing, "in front of, next to, behind." Though the book was small, I think this was a syllabus, because she had often checked off words or categories earlier in the list. She told me she would like to teach more English (she was allowed two thirty-minute periods a week), but the subject advisor set the time tables for this area. In Grade 2, students practiced only listening and speaking with a little reading. In the subsequent year, Standard 1, students would learn math in English. By Standard 3, instruction would change over to English in all classes, but the English teacher said it "was too difficult, because the students don't have enough vocabulary."

After we left a few things for the school, the stand-in principal graciously bid us goodbye, apologizing he could not offer us tea (no electricity) or a "proper toilet." Not long after we began walking down the dirt road, it started to rain heavily. We ran to a nearby leafless tree for a little cover and saw a senior primary boy and a younger one running toward us with two umbrellas. 
They stayed with us until the rain let up, smiling at our profuse thank yous, our chatter and laughter, and our gratuity for their thoughtful courtesy.

\section{O. Manquveni Primary School: Masibeka Primary School}

Our visit was led by EcoLink, a non-governmental organization that not only provided environmental awareness programs but did projects such as community gardens, sanitary toilets for schools, and community and school water tanks. The first school visited was extremely overcrowded with 1300 students and twenty-eight teachers. Some classes were held outside because of lack of space. The ground around the school was dirt with no vegetation near the school buildings. Some classrooms had broken windows. One classroom, vacant at the time of our visit, had no desks or seats, just the dirty cement floor. EcoLink was building a four-person ventilated improved pit toilet. The current toilet was not at all sanitary nor maintained.

The next EcoLink project was a school water tank at Masibeka Primary School, which had 600 students and eighteen teachers. Toilets were being built here as well. The school was about forty years old. There were cracks in the wall that went from the interior straight through to the exterior. The door jams were off so that the doors would not close. Teachers pointed out these structural deficits to us and were eager to show us the situation they faced. During a break the children came around us and happily gathered tightly together to fit into our photos.

\section{Summary of school visits}

The purpose of my visits to schools was to get an overall impression of the educational system and learn more about the culture as it was expressed 
in the schools. The teaching and learning situations I encountered reflect the two extremes that still exist in schools in post-apartheid South Africa.

With regard to the medium of instruction, the white schools were either taught in English or Afrikaans. Only one school of the six predominantly white schools I visited offered an African language, and it was an elective. Except for the predominantly black school (Penryn College) where English was used from Grade 1 on, English was the medium of instruction in a sudden changeover at Standard 3 in the nine all black schools. Principals of these nine schools all acknowledged that a great number of their students could not cope well with the changeover.

In all of the black schools where I interviewed principals, they expressed that parents supported their children learning English, which they felt would be a key to their future success. I found my brief visits corroborated what I read in Macdonald's (1991) book about bilingual primary education in South Africa regarding teaching methods and style, which was teacher-centered.

My observations in black schools and what was reported to me in interviews also illustrated the many references in the literature about lack of resources and impoverished school environments. I noted a shocking lack of reading material in the classrooms, and rarely any teaching aids beyond a chalkboard and chalk. When I finally located a copy of the teaching syllabus, it was a document that gave an overview of the principles of teaching the four language skills toward the goal of communicative competence. This would have been meaningless to teachers without accompanying training and follow up, as 1 was to see firsthand at a language teaching workshop in a rural teachers college. The teachers at the workshop were encountering this material for the very first time and were challenged in applying the concepts in role plays. 
Further workshops were necessary if these teachers were to successfully adapt these new methods in their lessons. Perhaps this lack of training and administrative support contributed to the reported and observed teacher absenteeism.

In Figure $\mathbf{4}$ which follows, I compare school environments of sixteen of the school visits I made. Schools are identified by the letters A-0 which correspond with their listing in this chapter. The two criteria most consistently related to the difference in environments are race and use of L1 or L2 as medium of instruction. The one black school that had a school environment like those of white schools was a new, private school with significant ties to a wellendowed, predominantly white school, that did fundraising and shared its educational expertise. The most glaring differences apparent from this chart are the result of vastly different resources provided to white schools and black schools, both in human resources (teacher-student ratio, teacher training) and material resources (reading materials, teaching aids, adequate facilities). Given the massive amounts of money needed for provision and improvement of housing, health care, job training and infrastructure, schools will compete with other deserving social requisites for limited resources.

The challenges ahead for the new government not only include redressing past inequities between white and black educational systems in areas such as increasing financial resources for black schools, improvement of teacher preparation programs, improvement of facilities, and curriculum development, but also resolving politically sensitive language issues which have negatively affected student retention, students' abilities to understand course concepts, and literacy, to name a few. 
Figure 4. Comparison of School Environments

\begin{tabular}{|c|c|c|c|c|c|c|c|c|c|c|c|c|c|c|c|}
\hline SCHOOL ENVIRONMENT * & A & $B$ & $\mathrm{C}$ & D & E & $F$ & G & $\mathrm{H}$ & 1 & J & $\mathrm{K}$ & $L$ & $M$ & $\mathbf{N}$ & $\mathbf{O}$ \\
\hline predominantly white school & $\bullet$ & $\cdot$ & - & 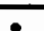 & . & 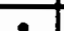 & & & & & & & & & \\
\hline home language (L1) as medium & $\bullet$ & $\cdot$ & $\bullet$ & $\bullet$ & $\bullet$ & $\bullet$ & & & & & & & & & \\
\hline predominantly/all black school & & & & & & & $\bullet$ & $\bullet$ & $\bullet$ & $\bullet$ & - & $\bullet$ & $\bullet$ & $\bullet$ & $\cdot$ \\
\hline L2 as medium(sr. primary on) & & & & & & & $\bullet$ & $\bullet$ & $\cdot$ & $\bullet$ & $\bullet$ & $\cdot$ & $\cdot$ & $\cdot$ & $\cdot$ \\
\hline sports equipment & $\bullet$ & $\bullet$ & $\bullet$ & $\bullet$ & $\bullet$ & n.o & $\cdot$ & & & $\cdot$ & & & & $\cdot$ & \\
\hline landscaped grounds \& fields & - & $\bullet$ & - & $\bullet$ & $\cdot$ & $\bullet$ & & & & & & & & & \\
\hline extra-curricular activities & $\cdot$ & $\bullet$ & $\cdot$ & - & $\bullet$ & n.o & $\bullet$ & & & $\cdot$ & $\cdot$ & & & & \\
\hline library & - & $\bullet$ & $\bullet$ & $\bullet$ & $\bullet$ & & $\bullet$ & & & & & & & & \\
\hline active parent support & $\cdot$ & $\cdot$ & $\bullet$ & $\bullet$ & $\cdot$ & $\cdot$ & $\bullet$ & & & & & & & & \\
\hline parental governance & $\bullet$ & $\bullet$ & $\bullet$ & $\bullet$ & & & $\bullet$ & & & $\bullet$ & & & & & \\
\hline ctass size $1: 35$ or lower & $\bullet$ & $\bullet$ & $\bullet$ & $\bullet$ & $\bullet$ & $\cdot$ & $\cdot$ & & & & & & & & \\
\hline cafeteria & $\bullet$ & $\cdot$ & $\bullet$ & - & $\cdot$ & & & & & & & & & & \\
\hline boarding facilities & $\bullet$ & $\bullet$ & $\bullet$ & $\cdot$ & $\cdot$ & & $\bullet$ & & $\bullet$ & & & & & & \\
\hline university-qualified teachers & $\cdot$ & - & $\bullet$ & - & - & $\bullet$ & $\bullet$ & & & & & & & & \\
\hline one desk, seat per student & $\cdot$ & $\bullet$ & $\bullet$ & $\bullet$ & $\bullet$ & $\bullet$ & $\bullet$ & & & & & & & & \\
\hline adequate teaching aids & - & $\bullet$ & $\bullet$ & - & $\cdot$ & $\bullet$ & $\bullet$ & & & & & & & & \\
\hline adequate \# books per student & $\bullet$ & $\bullet$ & $\bullet$ & $\bullet$ & $\bullet$ & $\cdot$ & $\bullet$ & & & & & & & & \\
\hline indoor flush toilets & $\bullet$ & $\cdot$ & - & $\bullet$ & $\cdot$ & $\cdot$ & - & & n.o & $\cdot$ & & & & & \\
\hline well maintained building(s) & $\bullet$ & $\bullet$ & $\bullet$ & $\bullet$ & $\bullet$ & $\bullet$ & $\bullet$ & - & $\bullet$ & & & & & & \\
\hline electricity & $\cdot$ & $\cdot$ & $\bullet$ & - & $\cdot$ & $\bullet$ & 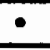 & - & $\bullet$ & $\bullet$ & $\bullet$ & & & & \\
\hline class size $1: 36$ or higher & & & & & & & & $\bullet$ & $\cdot$ & $\cdot$ & $\bullet$ & $\bullet$ & $\bullet$ & $\bullet$ & $\cdot$ \\
\hline outdoor toilets & & & & & & & & $\bullet$ & n.o & & $\cdot$ & $\bullet$ & $\bullet$ & $\cdot$ & $\cdot$ \\
\hline shared desks and seats & & & & & & & & $\bullet$ & $\bullet$ & $\bullet$ & $\bullet$ & $\bullet$ & $\bullet$ & - & $\cdot$ \\
\hline few/no books in classroom & & & & & & & & $\bullet$ & $\bullet$ & $\cdot$ & $\bullet$ & $\bullet$ & $\bullet$ & $\cdot$ & $\cdot$ \\
\hline little parent support & & & & & & & & $\bullet$ & $\cdot$ & $\cdot$ & - & $\cdot$ & $\bullet$ & $\cdot$ & - \\
\hline few/no teaching aids & & & & & & & & $\bullet$ & $\bullet$ & $\cdot$ & $\bullet$ & $\bullet$ & $\bullet$ & $\cdot$ & $\cdot$ \\
\hline building shows low maintenance & & & & & & & & & & & & - & & $\cdot$ & $\cdot$ \\
\hline & & & & & & & & & & & & & & & \\
\hline as observed or reported by & & & & & & & & & & & & & & & \\
\hline principal or teacher & & & & & & & & & & & & & & & \\
\hline n.o= not observed & & & & & & & & & & & & & & & \\
\hline
\end{tabular}


The following section relates discussions about these language issues on the part of the ANC political party, the government, and individual contributors who come mainly from the education community. This discussion is followed by the presentation of three educational models proposed by two non-governmental organizations active in the language policy area. The proposed models would promote the concept of multilingualism and other goals of the nascent language in education policy emerging from the current discussions and language planning activities. 
LANGUAGE POLCY DISCUSSIONS

\section{Discussions preceding the 1993 interim Constitution}

At the same time that academics were coming together to determine possible approaches to a new education and language policy (see NEPI, 1992), significant events in the early 1990's brought political blocs to the negotiating table to reorganize power in South Africa. There were many factors that brought the National Party to the negotiating table. Among them were the hampering of the economy by international sanctions, pressure from the U.S. and Great Britain, South Africa's two most important trading partners, to preserve their investment interests, the decline of influence of the military in the political system after South Africa's granting of independence to Namibia in 1991, and the collapse of socialism in Eastem Europe, which diminished National Party fears of an ANC - Communist Party take over (Crawhall, 1993).

The progressive bloc, headed by the ANC, was on the other side of the table. Its main motivation to negotiate was due to the changed attitude of the government and then-President de Klerk's initiatives, reduced military aid to the ANC by Gorbachev's restructured economy, and the expectation of winning a parliamentary majority in a free and fair election. Both sides had language policy as one of the issues to be negotiated. Although the ANC produced three significant sets of documents on language policy in the first years of this decade, it was willing to negotiate language issues (Crawhall, 1993).

Following are the discussion points and positions taken by many of the groups with an interest in the outcome of the language policy debate before the passage of the 1993 Constitution. 
The Nationalist bloc. Their sole interest was in the preservation of Afrikaans, owing to the Afrikaner ideological constructs of language, culture and nation. There was a range of positions within the viewpoint of retaining the status of Afrikaans, but maintaining an Afrikaans- medium educational infrastructure from primary through post-secondary was non-negotiable (Crawhall, 1993).

The South African Law Commission. The commission published a threevolume report on constitutional models, and language held a significant portion of that report. In the fifty-four pages of comparative studies and research on language, the report gave consideration to nine options, eight of which favored English as the official language or as one of two or more official languages, with the ninth option having an unspecified national unifying language. It evaluated the options based on their political viability, and cost and ease of implementation. It did not make conclusive recommendations but rather was a statement of principles for consideration (Crawhall, 1993).

The Dept. of National Education. The department produced the first government document on language in education policy in 1991, A Curriculum Model for Education in South Africa. It did not specify languages of instruction or subjects, but it did specify the number of languages, grade level, competency level, and if the language study would be compulsory or optional. It did not discuss the politically sensitive subject of what would constitute a regionally dominant language. It set a different but parallel debate on language issues. The following was the envisioned curriculum model (Crawhall, 1993):

Grade 1 one language compulsory (on the ordinary level); second language (basic level) optional 
Grades 2-4 two languages compulsory (ordinary level), one of which should be the mother tongue/medium of instruction

Grades 5-7 three languages compulsory, English, Afrikaans and the regionally dominant African language; two of them on ordinary level and one on the basic level

Grades 8-9 two languages compulsory (ordinary level); third language (ordinary level) or foreign language (foreign language level) optional

Grades 10-11two languages compulsory (on ordinary/advanced level); third language (ordinary level) or foreign language (foreign language level) optional

Grade 12 one language compulsory; second/third/foreign language optional; languages from ordinary/advanced level, foreign language on a foreign language level

The Threshold Project Researchers of the Threshold Project, set up by the Human Sciences Research Council in 1985, conducted a comprehensive study to determine the causes of educational failure in black primary schools. They concluded that a language policy should be based on the following principles (Macdonald \& Burroughs, 1991):

- language policy should aim to develop bilingual or multilingual speakers who see this as an important part of being South African,

- language policy should be an on-going process and open to periodic change to remain appropriate to changing times and circumstances, - language policy must foster parents' learning to be involved in educational choices, and should support parents' right to have their children educated in their own language, 
- all children should be given the option to learn English to become effectively integrated into multilingual, urban and industrialized society,

- language policy should be as fair as possible to all languages by supporting the development of indigenous languages, which could more easily be used as teaching languages.

The English Academy of Southern Africa. The Academy took positions in 1991 regarding language policy (Jenkins, 1991). It rejected the government's past use of indigenous languages as part of its policy of entrenching ethnic separatism, Christian National Education and apartheid. The Academy also did not see the maintenance of people's own language as essential for their advancement, should they prefer otherwise. To promote English or Afrikaans would have symbolic significance. The feelings associated with these symbols (e.g. English as a language of liberalism) should not be ignored in planning language policies. The Academy recognized the rights of other languages and did not claim an intrinsic superiority for English. The neglect of the African languages must be redressed.

In specific reference to language in education, the English Academy called for 1) involvement at the grassroots level (teachers and community) in decision making, 2) a distinction made between ideological and scientific arguments, and 3) a belief that ELTIC [English Language Teaching Information Centre, a nonprofit, democratic educational body committed to the improvement of English taught as a second language in Southern Africa] is qualified to advise and contribute to the policy debate. Further, the Academy recognized that no single model would suit all South Africa, so it did not advocate one particular pattern as its policy. 
The Dept. of Education and Training (DET). In 1992, this department, responsible for black schools and largely run by whites (later dissolved by the Constitution), decided to conduct a vote among parents in 7,368 schools to choose among mediums of instruction. The Minister would make the choice for those schools that did not vote. The purpose of the government strategy was not clear, but Crawhall (1993) saw this as democratic consultation at best as well as an attempt to bind future governments to similar tactics. It appears that it was an exercise that was not carried out conscientiously, as parents were provided scant information and little opportunity to consult with teachers. It did show a willingness on the government's part to take some action on language policy during the transition period.

The African National Congress (ANC). As previously stated, the ANC was open to negotiation on the language issue, and since the Nationalist bloc had a high priority to retain the status of Afrikaans, the Progressive bloc, headed by the ANC, was willing to make substantial trade-offs in this area for gains in other areas (Crawhall, 1993).

The ANC began its policy development when it participated in a workshop in Harare in March, 1990, one month after the unbanning of the organization. By 1992, the ANC had written a draft Bill of Rights recognizing eleven South African languages with no status distinction made among them. Recommendations for changes to the draft by Desai and Trew focused on articulating two types of linguistic rights: passive rights, those concerning the dignity and value of South African linguistic traditions, and positive rights, those protecting citizens from linguistic disenfranchisement.

The second set of rights marked a departure from the previous unimplementable category of cultural rights. The positive rights would be 
enforceable by the courts, and these rights had the capacity to transform the political and economic system by addressing the question of lack of access to resources and power (Crawhall, 1993). Desai and Trew commented, "Language rights need to deal both with...the unassailable position of English, and with the fact that African languages are the primary linguistic resource of most South Africans" (Crawhall, 1993, p. 21). With this philosophical and functional change, the ANC would move away from espousing multilingualism as an aspect of cultural rights to multilingualism as a national communications resource.

The next major document, ANC Policy Guidelines, was produced in May, 1992 by the Centre for Education Policy Development, a non-governmental organization set up by the ANC to draft discussion and policy papers. As a draft document, the guidelines were preparation for policy to come. In this draft the ANC determined three basic principles, mechanisms and stages of implementation, named the issues to be resolved, and anticipated objections. The following sets out the ANC policy framework which then led to the position paper of June, 1993, the year the interim Constitution was passed (ANC, 1993).

The policy is structured to provide interaction among three main principles:

- choice of languages: This was the heart of the policy and marked a historic shift away from the directive control of government and away from the generally directive pattern of post-colonial language in education policies in subSaharan Africa.

- the right of educational access to the development of such linguistic skills, in languages of their choice, as are necessary for full participation in national, 
regional, and local life. This principle moved the government away from imposition of particular languages towards provision or protection of access to necessary linguistic skills. The necessary skills referred to at least reading, fluent speaking, writing, and mastery of a range of discourses, but the term "linguistic skills" was essentially left undefined.

- affirmative action for languages whose status was reduced under apartheid. This principle signaled a commitment on the part of the government and provided indirect influence over educational choice of particular languages through the development of marginalized African languages.

These three principles, applied to the issue of mother tongue as medium of instruction would, for example, rule out the imposition of a particular medium of instruction at any stage, but through encouragement of affirmative action of African languages would make their choice more attractive to students.

In the section addressing mechanisms and stages of implementation, the guidelines looked at what mechanisms were left to affect language policy change after the withdrawal of the government from imposing compulsory requirements, such as medium of instruction. The initial lists included constitutional principles, legislation, transformation of existing institutions, regulatory functions of a ministry of education, public expenditures for resource development, public awareness programs and research, and incentives to choose languages whose status was reduced.

There is one section in the 1992 Guidelines that would be revised in the coming year because of its inconsistency with general ANC policy. In section N3 of the Guidelines, it stated that "ANC policy will further the development of all our languages, in all respects of life, in order to engender respect for different languages and to prevent the use of any language or languages for the 
purpose of domination or division" (ANC, 1993, Part 1, p. 11) and "All South Africans will have the right of educational access to the development of such linguistic skills, in the languages of their choice,..."(ANC, 1993, Part 1, p. 7) However, in Section $\mathrm{J} 4$ of the Guidelines, it stated that "all individuals must have access through their mother tongue and a language of wider communication to all avenues of social, political, economic and educational life. We are committed to providing access to a minimum of two languages - a regional lingua franca and English..." (underline theirs, ANC, 1993, Part 1, p. 6).

The Guidelines as written in 1992, including Section J4, were part of a larger education proposal announced to the public through the popular press and the ANC's publication Mayibuye. It was stated that "the ANC wants the National Education Board to use English as the teaching medium. Schools can decide which second or third language they would like to teach" (Weekend Argus, April 4, 1993; Mayibuye, April 30, 1993).

The general policy and guidelines were inconsistent in two respects. First, the introduction of language categories into policy was a political act and references to "language of wider communication" could entrench the status quo. Secondly, the basic principle of choice in the general ANC language policy (Section N3) was directly contradicted by the naming of English and categories of languages in Section $\mathrm{J} 4$ of the Guidelines (ANC, 1993, Part 1, p. 6-7).

By June, 1993, the ANC drafted a position paper addressing language in education. Following is a summary of the 1993 ANC's proposed general principles, which respond to the fourth guiding question of this study, principles underpinning a proposed policy. I also include their recommendations which pertain to my fifth guiding question about proposed models. The two aims of the policy are: 
1. to build on the linguistic strengths of learners and teachers and harness the rich multilingual reality of South Africa for effective education and effective participation in social, political and economic development, and 2. to create a policy environment which affirms the right of the individual to choose which languages to study and use as languages of learning (this document marks the introduction of their preferred term, 'language of learning,' in place of 'medium of instruction') (ANC, 1993, Part 2).

Proposed general principles :

1. redress: a new language in education policy will seek to redress the imbalances of the past,

2. access and empowerment: the state has an obligation to provide improved access to South African languages for all South Africans,

3. multilingualism: multilingualism is a national resource and must be promoted. Multilingualism at individual, institutional and social levels is one of the key aims, 4. flexibility: creative options, rather than a uniform policy, will help achieve our vision of multilingualism in a variety of different educational contexts, 5. facilitating communication: all South Africans will need to achieve a high degree of proficiency in not less than two, preferably three South African languages,

6. language and effective learning: since language is essential to thinking and learning, learners must be able to learn in the language(s) which best serve this purpose,

7. individual choice and institutional obligations: freedom of choice is a principle for individual learners. Educational institutions should be obliged to declare three South African languages as institutional languages and ensure that they are used in all operational aspects of their work, 
8. community-based decision-making: democratic community structures involving all affected constituencies, such as parent-teacher-student associations, should be responsible for shaping institutional language policy, within broad guidelines provided by the future democratic Constitution and detailed guidelines and criteria established by the Dept. of Education.

The ANC position saw several roles that English could play in a multilingual policy for education: 1) There is a great deal of valuable educational text in English in business, science, arts and other fields which should be made available to all learners, 2) all varieties of spoken English in South Africa are mutually comprehensible and should be accepted and valued in the educational system, so that (Standard British) English is not used for exclusion, division or domination, 3) all languages can and must be used for all purposes in all domains, and we must combat the perception that English is somehow a superior language, and 4) those innovative methodologies and materials developed for improvement of English language teaching are a transferable resource that can be applied to teaching any language or subject in any language (ANC, 1993, Part 2, p. 7).

To more fully describe the strong recommendation for bilingual, even multilingual education, the ANC made suggestions for possible models that suggested ways to implement language(s) of learning in the classroom, such as the following. One model would use a home language of the majority of the students in a particular school through school grades with other languages offered as subjects to take learners to a high degree of proficiency. Another could be a parallel bilingual model, where some subjects are taught through one medium while others are taught through the medium of another language. A third is a double medium model, where two languages are used interchangeably 
throughout (e.g. One week/day one language, one week/day the other language). A fourth is a partial bilingual model involving a switch to the target language (the straight-for option and sudden or gradual transfer options, though these are deficit models and run the danger of permanently entrenching the hegemony of the target language of instruction).

With regard to who would decide what the policy would be, the ANC suggested that decisions would be made by democratic institutional structures involving the whole institutional community, in consultation with the regional or subregional education authority.

\section{Interim Constitution and Language Policy}

South Africa's first democratic Constitution addressed the language issue in several sections. The Department of National Education (1993) published a brochure describing what the Constitution said about language policy. In general, the Constitution acknowledged and protected the diversity of language and culture. It affirmed the right of every person to use the language of his or her choice. Other provisions dealing with language, such as a person's communication with the State, rested on this basic right. So, too, is the Constitution's only reference (section 32) to language in education, that every person has the right "to instruction in the language of his or her choice, where this is reasonably practicable" (Dept. of National Education, 1993, p.3). Language in education policy, including decisions on medium of instruction, would have to conform to the spirit of the language provisions in the Constitution stated below.

The provision for eleven official languages in the Constitution is made as a democratic step intended to promote inclusiveness and, thus, national unity. 
The Constitution provided for conditions to develop and promote equal use and enjoyment of all official languages. It stated that the use of language for purposes of domination, exploitation or division must be prevented.

The Constitution gives certain rights to every person:

1. to basic education and to equal access to educational institutions,

2. to instruction in the language of his or her choice, where this is reasonably practicable, and

3. to establish, where practicable, educational institutions based on a common culture, language or religion, provided that there shall be no discrimination on the ground of race (Dept. of Education, 1995).

The 1993 government brochure anticipated the assumption that English might be expected as a sole official language. It explained that since a great majority of South Africans did not speak it as a home (or first) language, they would be disadvantaged, and that this would be an undemocratic step to take in a multilingual country.

\section{Post-1993 Constitution Discussions}

\section{Language Curriculum Framework For Compulsory General Education}

The purpose of this 1994 document, written by the Centre for Educational Policy Development which was commissioned by the Education Dept. of the ANC, was to suggest change mechanisms and processes to "support a flexible language policy which builds generic cognitive and linguistic skills across languages by building on the language strengths which learners bring to the classroom" (ANC, 1994, p.3). The framework was based on the fundamental principle that there would be two and preferably three institutional languages. It posited that change mechanisms would maintain and develop the language 
growth of learners in a way that previous curriculum frameworks, either through a forced changeover in medium or ignoring the actual language resources of learners, failed to do. "This is a fundamental issue of human rights, as well as human resource development" (ANC, 1994, p.3).

A related document, also by the ANC in 1994, The Policy Framework for Education and Training of the African National Congress, presented three general principles on which language policy should be based:

1. the right of the individual to choose which language(s) to study and to use as a language of learning (medium of instruction),

2. the right of the individual to develop the linguistic skills, in the language(s) of his or her choice, which are necessary for full participation in national, provincial and local life,

3. the necessity to promote and develop South African languages that were previously disadvantaged and neglected (Dept. of Education, 1995).

\section{Pan South African Language Board (PANSALB)}

The 1993 Constitution provided for the establishment of the PANSALB by the Senate. Legislated to be independent from the government, the board is responsible for assisting with the development of the official languages and must be consulted before any language legislation may be implemented. While the Constitution left language in the "grey and hazy domain of rights only," the PANSALB legislation dispelled much of the haziness by relocating language in a language-as-resource paradigm (Heugh, 1995a, p. 20).

Avoiding the ethnic divisions that represented past separate language boards and academies, the PANSALB Bill set the composition at fourteen members. Members appointed to the board would be people who support multilingualism, have specific language service and planning skills which go 
beyond a particular language, and are broadly representative of the population. In order to serve the interests of each language, the board is obliged to consult with all relevant people and organizations who have expertise or an interest in a language and its development. The general public is to make nominations, and the ad hoc Senate committee representing each province and political party is to interview in a public manner no more than fifty-two candidates. The full Senate will select from the recommended list of no more than twenty-six people from the first list.

Other powers and functions include promoting actively the development of previously marginalized languages, advising government on financial or other support needed by groups whose language rights are violated and investigating those alleged violations, and establishing provincial language committees to advise on provincial needs (Heugh, 1995a).

\section{Towards a Language Policy in Education: Discussion Document}

This Dept. of Education document, dated November 1995, was designed to update and clarify earlier reports, and represented a step towards the removal of linguistic and racial discrimination in language policy in education. It was to be used as a discussion document and a contribution to the continuing work on language in education policy. The document summarized themes and tensions in other source documents, listed recent amendments to a policy document, commented on current requirements, discussed opportunities for strategic intervention in the immediate and long term issues, and made recommendations on those issues. In addition, the authors of this document thought that it was crucial that school communities were given the rationale underpinning changes in policy, so for the first time there is a section included on the rationale for proposed policy decisions. 
The document discusses many specific concerns and issues that need immediate and longer term attention. I will focus on one part of the discussion document that noted the closely related policy areas that are key to the success of the larger language in education policy: curriculum development, resourcing and governance. These three key policy areas give some tangibility to the policy issues, which are often discussed in abstract terms. All three areas need to be consciously and strategically interwoven in the field of language policy.

Seen holistically, curriculum development encompasses teacher development, materials development, syllabus change and assessment practices. Without sound curriculum development, language policy change can only be cosmetic. Key opportunities are the possible establishment of provincial and national institutes for curriculum development and the development and implementation of a national qualifications framework (NQF). The NQF is a qualifications "jungle gym" on which all qualifications in the future are to be registered. It basically will impose an outcomes-based approach on curriculum development and assessment on all education institutions across the board (Luckett, personal communication, 1997). A central instrument for transformation of the education system, the NQF emphasizes open learning, core knowledge and skills, the integration of education and training, mobility of learners and recognition of prior learning.

Resourcing a language policy can be seen in both human and material terms. Most students have access to teachers who speak their language, but those teachers' linguistic resources must be used more effectively. For those students who don't have such teachers, urgent remedies must be found to 
provide for that need. As to material resources, more provision of learning resources must be made, especially in the area of African languages.

Democratic governance in education is critical. New policies will fail without the active support and commitment of parent, teacher, and student constituencies among others. Without the understanding of local contexts, language plans for schools are "doomed to over-simplification, overgeneralisation or simply to irrelevance" (ANC, 1995, p.12).

The Dept. of Education sees two aspects of a strategic vision for a new language in education policy that it must urgently address. First, it strongly recommends that additive bilingual models should become a central feature of education policy. The deficit models that largely characterize South African schools past and present have excluded African languages as vehicles of learning from all except the early grades. Secondly, a new language assessment and qualifications framework needs to be designed that correlates with the National Qualification Framework.

As the discussion document notes, "A proactive, creative and sensitive language policy in education must have holistic strategies and interlocking structures to make it meaningful" (Dept. of Education, 1995, p. 13). Put another way, "...multilingualism will remain an empty concept unless it is given content" (Heugh, Siegrühn, \& Plüddemann, 1995, p. v).

\section{Other Contributors to the Language in Education Policy Debate}

The following writers, mostly from the education sector, also contributed to the ongoing debate about language policy issues. They made valuable observations and put forward personal opinions for consideration. I have selected quotations from their articles, speeches and interviews so that the 
strength of their convictions is presented undiminished in their own words. Each quotation reflects a key point the author made in his or her discussion of language issues which affect policy development.

Most of the following contributors did not directly work in policy making arenas, such as NEPI research or Centre for Education Policy Development, but as academics in language teaching or linguistics or spokespersons for social institutions, their contributions add value to policy discussion and development. They are included here to complement the government's language policy discussion and positions, giving the reader a more complete picture of national discussion.

Njabulo Ndebele, University of the North, delivered the keynote address at the Jubilee Conference of the English Academy of Southern Africa in 1986: "English is an international language, but it is international only in its functionally communicative aspects. For the rest of the time, indigenous languages fulfil the range of needs that English similarly fulfils for its native speakers. From this point of view, the functional acquisition of English in a capitalist society such as ours can further reinforce the instrumentalization of people as units of labour...Indeed, in the same way that grassroots organisations are meant to protect people from the oppressive impersonality of the state, indigenous languages can be a refuge away from the manipulative impersonality associated with corporate English language acquisition" (Ndebele, 1987, p.14).

Peter Titlestad, Pretoria University: "...market forces [the right of choice with regard to the language of education and business] will play a role in ensuring the future growth of English in South Africa and that South Africa is fortunate to have among its languages one that can perform so many important functions" (Titlestad, 1996, p. 163). "Not to allow English to 
perform the functions it can would be infinitely harmful to the development of South Africa and its people" (p.172).

Vic Webb, Pretoria University: "It is far more likely that, in reality, less than $25 \%$ of the black population of South Africa know English well enough to be able to become empowered through it, i.e. to obtain meaningful access through it to educational development, economic opportunity, political participation and real social mobility. If this is the case, government policy makers should not, at present, expand the domains for which a knowledge of English is necessary, since such a decision may easily lead to elitism and discrimination" (Webb, 1996, p. 178-9).

Barbara Bosch and Vivian de Klerk, Rhodes University: "Language attitudes (both on a conscious and sub-conscious level) ought to be taken into consideration when formulating an education policy for the Eastern Cape....Language attitude studies provide important information for the language planner...and illustrate the necessity for wider consultation within an educational framework in devising new language policies and practices with respect to education, that reflect the wishes of the people" (Bosch \& de Klerk, 1996, p. 246-7)

Ken Hartshorne, Dept. of Education: "Language issues...have to be approached with respect, tolerance and a deep sense of regard for the rights of individuals in society. Above all, ... whatever national policy is decided upon, it must be flexible in concept, implementation and practice. Flexibility will prove to be the key to a broadly acceptable and legitimate language policy that will be capable of responding to the needs and wishes of a wide-ranging variety of South Africans in a diversity of language situations" (Hartshorne, 1995, p. 317). 
Wally Serote, Dept. of Arts and Culture, ANC: "There is some form of transformation which languages like English and Afrikaans must go through, a transformation where everybody in South Africa would look at them and say that these are our languages because they are South African languages.

English itself needs to be developed so that people have access to it, so people don't have negative attitudes towards it. But all South African languages need to be developed. It is on the basis of that, that we think a democratic culture will emerge in this country" (Wade, 1993, p. 55).

Donna Kerr: Kerr suggests four tests that a good public policy must pass: "1) the desirability test. Is the goal of the policy one that the community as a whole believes to be desirable? 2) the justness test. Is the policy just and fair? That is, does it treat all people in an equitable and appropriate manner? 3) the effectiveness test. Is the policy effective? Does it achieve its objectives? 4) the tolerability test. Is the policy resource-sensitive? Is it viable in the context in which it is to be effected?" (Reagan, 1995, p. 320).

T.G. Reagan: "What is needed...(are) language policies devised in consultation with, and with the support and involvement of, those they are intended to serve...those involved in language planning activities must approach these activities in a less technicist, more democratic way, for the good of all South Africans" (Reagan, 1995, p. 327).

S. Murray and $H$. van der Mescht, Rhodes University: "Over the last two or three years [1992-94], there has been an increasing emphasis on multilingualism in educational debates, and in some cases a demotion of the importance of English. Perhaps unsurprisingly this has happened at a time when, in the political arena. English is used increasingly at the expense of other languages, and when English is actually growing in importance as a medium of 
instruction in schools, colleges, technikons and universities...What is clear is that in a new unitary national education system, in which schools are likely to be predominantly English-medium, English teachers will bear a heavy responsibility for ensuring equal access to learning for all students" (Murray \& van der Mescht, 1996, p. 254-5).

Neville Alexander, University of Cape Town: "What we do still lack is the political will, in other words there are among the major political organisations, if not indifference in most cases, a relative hostility to a multilingual approach, mostly because it is convenient, and you can keep the power amongst a very small elite if English remains the most important language..... In fact that [the danger that parents could be brainwashed to think that their home language is inferior] has happened in South Africa. We have a major problem because people clearly begin from economic considerations; English or Afrikaans even, as the languages of power and they begin to play down the importance and status of their own languages so that teachers have a big backlog to persuade parents to let children learn their own language. But I think that is a battle we will win" (Alexander \& Smolicz, 1993, p. 7).

David Gough, Rhodes University: "The general point is that multilingual ability--knowing each other's languages--does not in itself lead to mutual understanding and decolonisation...It is obvious that the consequences of mutual multilingualism are strongly contingent on the socio-political context in which it occurs. In this sense, multilingualism is not positive or negative in itself, and we should be cautious in labeling it either way" (Gough, 1994, p. 9)

Winnie Mandela, then-Deputy Minister of Arts, Culture, Science and Technology: "While we insist on individual language rights, we should not lose sight of the notion of national unity... (which) will emerge when individuals feel 
proud of being South African. When individuals feel proud of their arts, language and culture, when they can celebrate the diversity of their languages and cultures and still be South African" (Mandela, 1994, p.6-7).

Kathy Luckett, National Language Project: "A critical language awareness, which helps our school communities to understand the relationship between language, power and social structure should also be promoted. Without such a campaign, it is unlikely that parental choice will be exercised on the basis of "common sense" and (that) the first challenge...[for the central education authority to draw up a comprehensive national framework offering a variety of bilingual models from which to local school bodies can choose] will be met. Instead, freedom of choice will simply pave the way to assimilation to the dominant language and culture and the hegemony of English will be reinforced" (Luckett, 1993, p.57-8).

\section{Summary}

The contributors quoted above wrote articles focusing on a number of different aspects in the language policy area. While not all contributors addressed the same issues, there were several opinions held in common in their articles.

A major concern of these writers is that the power of English in South Africa and its increased use in various domains is at the expense of other languages. English can continue to be used as a tool to exclude Africans from full participation in the economic life of the country and can further entrench elitism. A language awareness campaign on the part of the government can challenge the preference of parents for their children to do their studies through the English language. This preference is made on the assumption that 
an English-medium education will benefit the children economically when they look for a job. Only political will and implementation of multilingual approaches in education and in social institutions will reverse this trend, otherwise the hegemony of English will be reinforced. African languages can fill an important role in education and in society.

Democratic governance is another major concern. Language attitudes and the wishes of the people must be considered in language planning for the policy to be effective, and language rights should be regarded with respect and tolerance. Furthermore, the policy should be just and fair to the various linguistic groups. Flexibility in language policy will allow local and regional needs and wishes to be considered. Since there is an expressed desire for English in schools, students should have more meaningful access to learning English through improved teacher preparation, curriculum development, and greater human and material resource allocation.

Gough (1994) makes a provocative point about multilingualism, a central principle in the language policy being developed. He cautions that it is the socio-political context in which multilingualism occurs, not multilingualism per se, that will lead or not lead to mutual understanding and decolonization. Language planners should recognize that multilingual approaches alone will not redress past inequities but must work in concert with other broad societal changes to accomplish that goal. 


\section{PROPOSAL AND MODELS}

The proposal and models presented here are published by the National Language Project and The Project for the Study of Alternative Education in South Africa (PRAESA), both non-governmental organizations (Heugh, Siegrühn, \& Plüddemann, 1995). It is an effort to provide models that would ensure the implementation of nascent language in education policies in ways that promote multilingualism and African languages in particular, while guaranteeing access to English, the current language of power.

\section{Kathy Luckett: National Additive Bilingualism}

Luckett points to a key issue that must be taken into account in language planning if the current plan is to succeed. Everyday attitudes about language will govern people's choices about what languages they will learn at school (Luckett, 1995). Those dominant attitudes are 1) speakers of African languages have been denied meaningful access to English, a language which enables people to get ahead in life; also it is believed that proficiency comes with the longest exposure, and the sooner the better, 2) it is believed that African languages are not suitable for functions that English now fills, like higher education, science and technology, business, law and government, and are, therefore, of less value, and 3) a person's status is often measured by his or her proficiency in English.

Luckett recognizes that promotion and development of African languages goes against most people's common sense, and that as long as people believe that proficiency in English is the only way to get ahead, the power of English will remain intact. She further recognizes that it is very unlikely 
that there will ever be enough human and material resources to ensure everyone has equal access to English, resulting in the present situation where a majority of people will be denied power and privilege because their English is not good enough.

To counter these current realities, Luckett proposes the use of state power and resources, as there once was for developing Afrikaans, and a national language awareness campaign to recover the value of African languages as a national resource. The challenge may be the black middle class who, having access to state power, are in a position to promote the enhanced status of African languages. Yet this black middle class has access to education, well paid jobs and political and economic power due to their proficiency in English.

The term "national" in "national additive bilingualism" indicates that this policy applies to all South African students. "Additive bilingualism" implies that a student gains competence in the second language while the first language is maintained. Both languages must be used as mediums of instruction at some stage in the curriculum. Both languages and cultures must be valued for the biligualism to succeed.

Luckett draws on research by Cummins and Macdonald to support her proposal. Cummins distinguishes between two levels of language learning, "basic interpersonal communicative skills" (BICS) and "cognitive/academic language proficiency" (CALP). Cummins claims that the two languages of a bilingual can develop independently to the BICS level, i.e. students are able to communicate in everyday contexts in both languages. However, when it is necessary to use language in a more cognitively demanding situation, such as abstract thinking or decontextualized situations, a student's ability in the 
second language to operate at the CALP level depends to some extent on the stage of development reached in the first language.

Macdonald's (1990) research found that students could not explain in English what they knew in their first language, nor could they transfer into their first language what they learned through English. They failed to achieve the cognitive/academic level of language proficiency in either language. In an additive bilingual situation where the first language is maintained, students will be able to reach CALP in the second language, because the cognitive skills they acquired in the first language are easily transferred to the second language.

Luckett suggests a language plan that follows a model such as this:

- Preschool: sound development of L1

- Primary: three languages are offered, one of which is English or another language of wider communication, another is the regionally dominant language (if there is one), and a third one which is optional that is chosen by the parents of the school. English is introduced as a subject in the first or second year, while cognitive skills are developed in L1. As students' English skills improve, English can be introduced as medium of instruction in other subjects, one at a time.

- Secondary: All schools should offer at least four South African languages. The learning of a third language should be strongly encouraged. Students should continue to develop L1 to a cognitively demanding level (CALP), taking L1 as a subject as well as medium of instruction for some subjects and not just marginal subjects like religious education and music as in current practice. English would be taught as a subject and medium of instruction for some subjects. 
- Post-compulsory: during the last three years of secondary school leading up to the proposed Further Education Certificate, the focus should be on preparing for vocational training or higher education. Depending on the choice, the student would develop first and second language skills in that area.

In the short term, language planners see English as a linking language. As the status of other South African languages is enhanced, planners predict that the dominant role of English will diminish. Changes envisioned include teaching methods and redefining what is meant by "standard English." There must be affirmative action efforts for African languages as well as development of the languages to handle cognitively demanding content, new curricular materials, teaching methods and reading resources.

\section{Neville Alexander: Multilingual Schooling}

Alexander's three models support a national additive bilingual position. He considers it a high priority for the leadership of South Africa to invest in the educational sector to guarantee a democratic future. Alexander asserts that only a committed campaign by political, economic and cultural authorities during the next few years to enhance the status of African languages can counterbalance the strong pressure on non-English speakers to target English as a language of learning (medium of instruction) and straight-for-English or other subtractive bilingual models (Alexander, 1995).

The first model has $L 1$ as the language of learning for all subjects across the curriculum for the first four grades. See Table II for representation of this model. In Grades 1 and 2, L2 (English or another) is introduced orally, moving from mainly listening skills to speaking skills including songs and rhymes. Grades 3-4 add reading, and writing is introduced gradually. In Grade 5, L1 is still 
taught across the curriculum except for math and science, which is likely to be in English for most students, as at present. L3 is introduced emphasizing oral skills. In Grades 6-12, both L1 and L2 are languages of learning, with the proportion of subjects taught in each to vary according to local circumstances determined by parents, teachers and students. L3 continues with oral skills and in Grades 9-12, L3 becomes a subject. In Grade 13 there is preparation for higher education in both $\mathrm{L} 1$ and $\mathrm{L} 2$.

This model depends on improved training of teachers in both English and African languages as well as development of teaching materials in African languages. It further requires a complete overhaul of most teacher education programs to accommodate the language across the curriculum and integrated studies approach.

The second model is a medium-term option as it has L1 as the only language of learning. Alexander supports exposing the fallacy that proficient competence in English can only be achieved when it is a language of learning. He feels that as the status of African languages grows, the perceived need for English as medium will decline. Students with different first languages could still be educated in the same school but in different language streams, but this option would depend on political developments, which cannot be anticipated at this time.

The third model, the immersion model, would also be a longer term option, yet a real possibility for English-and Afrikaans-speaking children who would enter an immersion program in an African language in their senior primary or junior secondary years when they will have consolidated their first language. All teaching would be in L2 except for the teaching of L1 as a subject. 
Supporting the establishment of the first model, the most viable at this time, Alexander, Director of PRAESA, and his staff are laying the groundwork for a demonstration school, preferably one in each province. There would be an accompanying teacher training module, which would provide a dynamic 
TABLE ॥

ALEXANDER'S MODEL OF A MULTI-MEDIUM SCHOOL

\begin{tabular}{|c|c|c|c|c|c|}
\hline \multicolumn{2}{|c|}{ PRESCHOOL } & \multirow{2}{*}{$\begin{array}{l}\text { L1 emphasized } \\
\text { but not forced } \\
\text { L1 across the } \\
\text { curriculum }\end{array}$} & \multicolumn{3}{|c|}{$\begin{array}{l}\text { Spontaneous usage of all language } \\
\text { varieties in child's environment }\end{array}$} \\
\hline GRADE & 1 & & \multicolumn{2}{|c|}{$\begin{array}{l}\text { L2 oral (mainly } \\
\text { listening skills }\end{array}$} & \\
\hline GRADE & 2 & $\begin{array}{l}\text { L1 across the } \\
\text { curriculum }\end{array}$ & \multicolumn{2}{|c|}{$\begin{array}{l}\text { L2 oral (more } \\
\text { emphasis on } \\
\text { speaking skills) }\end{array}$} & \\
\hline GRADES & $3-4$ & $\begin{array}{l}\text { L1 across the } \\
\text { curriculum }\end{array}$ & \multicolumn{2}{|c|}{$\begin{array}{l}\text { Consolidation of } \\
\text { L2 reading skills; } \\
\text { writing introduced } \\
\text { gradually }\end{array}$} & \\
\hline GRADE & 5 & $\begin{array}{l}\text { L1 across the } \\
\text { curriculum except } \\
\text { Maths and Science }\end{array}$ & \multicolumn{2}{|c|}{$\begin{array}{l}\text { Maths, Science in } \\
\text { L2 (most like } \\
\text { English for most } \\
\text { pupils) }\end{array}$} & $\begin{array}{l}\text { L3 introduced with } \\
\text { emphasis on oral } \\
\text { skills }\end{array}$ \\
\hline \multicolumn{6}{|c|}{$\begin{array}{l}\text { In the next phases (Gr } 6-12 \text { ) of the curriculum, the proportion of subjects } \\
\text { provided in } L 1 \text { and } L 2 \text { will vary according to circumstances determined by } \\
\text { parents, teachers and students. Technical and career-related considerations } \\
\text { will affect the choice of medium. }\end{array}$} \\
\hline GRADES & $6-8$ & \multicolumn{2}{|c|}{$\begin{array}{l}\mathrm{L} 1 \text { and } \mathrm{L} 2 \text { as language } \\
\text { of learning }\end{array}$} & \multicolumn{2}{|c|}{ Oral skills in L3 consolidated } \\
\hline GRADE & 9 & \multicolumn{2}{|c|}{$\begin{array}{l}\mathrm{L} 1 \text { and } \mathrm{L} 2 \text { as language } \\
\text { of learning }\end{array}$} & \multicolumn{2}{|c|}{$\begin{array}{l}\text { L3 formally introduced as a } \\
\text { subject }\end{array}$} \\
\hline GRADES & $10-12$ & \multicolumn{2}{|c|}{$\begin{array}{l}\mathrm{L} 1 \text { and } \mathrm{L} 2 \text { as language } \\
\text { of learning }\end{array}$} & \multicolumn{2}{|c|}{ L3 as a subject } \\
\hline GRADE & 13 & \multicolumn{2}{|c|}{$\begin{array}{l}\text { Preparation for post- } \\
\text { secondary education: } \\
\text { research and study } \\
\text { skills in } L 1 \text { and } L 2\end{array}$} & & \\
\hline
\end{tabular}


learning environment where research and teaching practice are integrated and add to ongoing knowledge about teaching and learning in a multilingual context.

\section{Kathleen Heugh: Modified Dual Medium}

A dual medium model involves teaching and learning through two languages as mediums of instruction. This model is modified from an earlier model serving English and Afrikaans speakers, especially during the first half of this century. Large scale studies conducted in 1938 by the National Bureau of Educational and Social Research, published in 1943 (cited in Heugh, 1995b), indicated that dual-medium instruction was one of the factors responsible for the high degree of English-Afrikaans bilingualism and good social relations between the two communities. This model was virtually phased out after the National Party came to power in 1948.

The dual medium model is similar to the multilingual model above in that $\mathrm{LI}$ is maintained throughout and is the dominant language for cognitive development. The second and optional third language is added to L1 at the beginning of schooling and knowledge is transferable to L2 and L3. African languages are promoted as valid languages of learning. L3 is optional and the timing of its introduction and sequence of language skills taught is determined at the local level by the school community (Heugh, 1995b).

The main difference between this model and Alexander's model is that L2 (English in most cases) is used as a second medium of instruction alongside L1 in all content subjects from Grade 4 onwards, and not be reserved for math and science. Heugh's model allows for flexibility in the phasing in of the dual medium approach, but L2 teaching/learning time should not exceed fifty per cent of total instruction. See Table III for a representation of Heugh's model. 
TABLE III

HEUGH'S MODEL FOR A DUAL MEDIUM, MULTILINGUAL SCHOOL

\begin{tabular}{|c|c|c|c|}
\hline $\begin{array}{l}\text { KIndergarten/ } \\
\text { Preschool }\end{array}$ & $\begin{array}{l}\text { Facilitate } \\
\text { emergent literacy } \\
\text { L1 oral skills } \\
\text { development }\end{array}$ & $\begin{array}{l}\text { Facilitate } \\
\text { emergent literacy } \\
\text { L2 oral skills } \\
\text { introduced }\end{array}$ & $\begin{array}{l}\text { Facilitate } \\
\text { emergent literacy } \\
\text { L3, as an option, } \\
\text { oral skills } \\
\text { introduced }\end{array}$ \\
\hline GRADE 1 & $\begin{array}{l}\text { L1 literacy } \\
\text { established }\end{array}$ & $\begin{array}{l}\text { L2 oral skills } \\
\text { consolidated }\end{array}$ & $\begin{array}{l}\text { L3 oral skills } \\
\text { introduced/ } \\
\text { consolidated }\end{array}$ \\
\hline GRADE 2 & $\begin{array}{l}\text { L1 literacy } \\
\text { reinforced; } \\
\text { cognitive } \\
\text { enrichment via L1 }\end{array}$ & $\begin{array}{l}\text { L2 oral skills } \\
\text { consolidated }\end{array}$ & $\begin{array}{l}\text { L3 oral skills } \\
\text { consolidated }\end{array}$ \\
\hline GRADE 3 & $\begin{array}{l}\text { L1 literacy } \\
\text { reinforced } \\
\text { cognitive } \\
\text { enrichment via L1 }\end{array}$ & $\begin{array}{l}\mathrm{L} 2 \text { reading and } \\
\text { writing introduced }\end{array}$ & $\begin{array}{l}\text { L3 oral skills } \\
\text { consolidated }\end{array}$ \\
\hline \multicolumn{4}{|c|}{$\begin{array}{l}\text { At this point, dual-medium instruction would begin. Depending upon the } \\
\text { linguistic conditions in the school and language levels of the students, it may } \\
\text { be possible to move into a } 50-50 \text { situation, whereby two languages have an } \\
\text { equal proportion of time in the content classes. However, in some schools } \\
\text { where most of the students have the same } L 1 \text {, it may be more practical to } \\
\text { phase in the dual-medium approach, i.e. gradually increasing the } L 2 \text { content } \\
\text { until the } 50-50 \text { stage is reached. For most students, the } L 1 \text { will be an African } \\
\text { language and the chosen } L 2 \text { will be English. English- and Afrikaans-speaking } \\
\text { students will be encouraged to select an African language as their } L 2 \text { and } \\
\text { second medium of instruction. However, conditions need to be created to } \\
\text { ensure that, as a minimum requirement, these students take an African } \\
\text { language, at the very least, as a subject, i.e. as } L 3 \text {. }\end{array}$} \\
\hline GRADE & L1 & L2 & $\begin{array}{l}\text { L3 oral skills } \\
\text { consolidated }\end{array}$ \\
\hline GRADES $\quad 5-7$ & L1 & L2 & $\begin{array}{l}\text { L3 introduced } \\
\text { formally, if not } \\
\text { already done }\end{array}$ \\
\hline GRADE & L1 & L2 & $\begin{array}{l}\text { L3 reading and } \\
\text { writing introduced, } \\
\text { if not already } \\
\text { done }\end{array}$ \\
\hline GRADES & LI & L2 & $\begin{array}{l}\text { L3 examinable } \\
\text { subject }\end{array}$ \\
\hline
\end{tabular}




\section{CHAPTER 5}

\section{DISCUSSION}

In the first four chapters, I have attempted to provide a foundation and context through my research and guiding questions for the reader to understand South Africa's efforts to develop a new language in education policy. I prepared the context by drawing from a number of resources. The context includes an historical overview of the country's education system and its language policy, a discussion of language planning and policy issues from the perspective of various theoretical frameworks, educational research and surveys, and the role of English in other African Educational systems. It also includes findings drawn from three sources in order to provide a more complete picture of the discussion of language policy issues. These sources are my firsthand visits to South African schools, a review of government discussion and position papers, and a review of articles from professional journals and the popular press regarding language in education policy.

My firsthand visits provided an invaluable piece of research on the complex issue of the place of languages in education. It was a concrete experience to actually see and hear about what local schools and local, regional and national administrations must grapple with in their efforts to improve the ability of students to achieve their educational potential. To see language classrooms without reading materials was to understand more fully the enormous gap that exists and must be remedied. To hear principals tell me that their students had a difficult time and often couldn't cope with the 
changeover to English as medium of instruction impressed me with the challenges facing teachers, curriculum specialists, and teacher trainers to change the system from the ground up, providing a meaningful access to students' own languages and to English.

The primary sources from within and outside government that I received from South Africa confirmed their acknowledgment of language in education policy as one that deserves careful yet deliberate action. The information drawn from these sources provided ample evidence to answer my guiding questions. The questions guiding this case study are discussed in the first section of this chapter. The discussion in the guiding questions draws from this study's previously reviewed literature and school visits. Suggestions for further research, implications for the TESOL practitioner, and my concluding thoughts round out the chapter.

\section{RETURN TO GUIDING QUESTIONS}

The failure of the education system for the great majority of black students and black teachers is apparent to both the researcher and the observer. Many policies underlie this failure, and language policy is recognized as one important contributor. My research attempted through my guiding questions to assess the direction South Africa is taking during this transitional period in redressing this failure as it concerns language in education policy. The questions sought to determine the context of the language situation, such as the influences of South Africans' attitudes toward English and the influences of South Africa's historical past. The questions also sought to determine what 
principles the new government is proposing as the foundation upon which a new language in education policy will stand.

The critical factors that will most likely determine the ultimate success or failure of the policy, or some point in between the two extremes, will be the accompanying social, economic and political situations in which the language policy will operate. These situations are not only unpredictable but are well beyond the scope of this research. Nonetheless, the intentions and positions of the government and those in education and the private sector who are taking part in the policy debate are critical considerations in charting the course of transforming the education system as well as other institutional changes. Following are summary discussions of the findings of my guiding questions.

What are the attitudes towards English in schools?

In government discussion papers, language preference and language attitude surveys, and academic articles, English is referred to in terms such as prestige, high status, dominant, power, magic, lingua franca, language of liberation, language of wider communication, universal language, a stepping stone to higher paid employment, and language of access to the wider world, particularly in financial, commercial, technological, information and academic fields. Further, many of these sources, including the government, often refer to the hegemony of English. Nelson Mandela, who garners high respect and even reverence among South Africans and who speaks several languages, speaks English to his fellow citizens and to world leaders.

The rejection of African languages as mediums of instruction, the policy of the Nationalist government from the 1950's to the 1990's, was categorical (Msimang, 1996). The rejection of African languages also got entangled in the 
rejection of Afrikaans, which led to the Soweto Uprising in 1976. The government policy, which forced increasing instruction in the home language beyond Standard 3, was rejected not because parents and students did not value African languages, but because these languages did not enable them to compete in the job market with whites, excluding them from the country's economy, the ulterior motive of then-President Verwoerd. When the opportunity to attend white schools was offered to blacks, they "seized it with both hands" (Msimang, 1996, p. 2). Given this still recent history, a crucial question is whether parents will change their minds and attitudes this time around about the value of African languages in school.

That English is powerful and desirable is not disputed, nor is the fact that English will play a significant role in schools as a medium of instruction. The challenge facing those in South Africa who favor multilingualism and redressing the de facto low status of African languages is to make people aware of the educational benefits of literacy and cognitive development in the first language which will also ultimately enhance the learning of English. Heugh (1995) has warned that only by changing attitudes toward the relative value of English and the other South African languages will the status quo be changed.

What do the school visits in this study reveal about language in education issues?

One of the most frequently encountered phrases in the articles and documents I read was that students needed "access to English." Considering students were taught through the medium of English from Standard 3 on, it appeared on the surface that students did have access to English. The school visits revealed that this phrase meant that the educational system does not 
provide students with meaningful access to learning English. There are many contributing factors to this situation that I saw firsthand or had reported to me in interviews.

One critical reason cited in the literature for the lack of meaningful access to English was poorly trained teachers. Although many teachers that 1 observed had a very good command of English themselves, their teacherdirected lessons tended to focus on grammar points rather than using the language for real purposes. Exceptions were writing exercises where students conveyed personal responses to a given topic, and in the early grades learning English by using movement as an learning aid such as in a total physical response methodology. Many teachers were reported by their principals to have some teacher college preparation, but that training was acknowledged by education administrators I spoke with elsewhere to be quite insufficient for good classroom teaching.

Another important factor is the general absence of reading material. Occasionally I saw one set of a children's book sitting on a desk, donated or loaned by READ, a non-governmental organization. Absent to an even greater extent was reading material in African languages (I saw none). Another example of insufficient preparation for the medium change besides lack of reading material was the little time spent on English in the early grades, as little as two 30-minute periods a week. Curriculum, languages studied, and time allotted to each subject was controlled by a central administration, and local schools were not given the flexibility to make alternative choices.

High class sizes also contributed to fewer opportunities for teachers to hear and help individual students with their language learning. The environment outside school in the rural areas I visited provided virtually no possibility to use 
any English learned in the classroom or to hear English used in non-classroom contexts except perhaps American music on a battery-operated cassette player.

The other issue that I encountered on my visits concerning the teaching of English is the positive attitude toward the language by principals, teachers and students and, as reported by the principals, this attitude is shared by parents as well. English will definitely retain its central focus in schools even if a multilingual approach is successfully introduced. English is perceived to have great value, and there is demand for it.

Who are the participants in the language policy debate?

In my survey of the language in education policy discussion, I received numerous articles and discussion papers that were written by three general sources, 1) academics associated with South African universities, 2) education departments of the ANC, the political party, and of the ANC-led national government, and 3) non-governmental organizations (NGO's), such as the National Language Project, The Project for the Study of Alternative Education in South Africa (PRAESA), English Language Teaching Information Centre (ELTIC), and the Centre for Education Policy Development, an NGO funded mostly by the European Economic Community and set up by the ANC Education Dept. before the ANC came to power.

From the 1950's until the 1970's there was no public debate on language policy from the anti-apartheid groups. It was a period when the Nationalist government imposed the grouping of people by the languages they spoke onto the country without opposition (Louw, 1992). From the mid-1970's to the mid-1980's, Black Consciousness supporters challenged the 
language policy, proposing having only English as the national language. A significant shift came about in 1989 with Alexander's proposal, which advocated English as the official language nationally with the other languages given official status regionally (Alexander, 1989, in Titiestad, 1996). Titlestad (1996) credits Alexander with "alerting us to the need for language planning" (p.166).

According to reference sections following articles on language in education policy that I reviewed, there were a few notable contributions toward making changes in language policy before 1990: Ndebele's 1986 keynote address to the Jubilee Conference of the English Academy of Southern Africa, the Nhlapo-Alexander Proposal to restandardize the Nguni (Xhosa and Zulu) and Sotho (Northern and Southern Sotho) languages to help restore the structural inequities and promote multilingualism, and Alexander's book, Language Policy and National Unity in South Africa/Azania (1989).

As the political situation began to change dramatically about this time and with the publication of Macdonald's comprehensive research in 1990 exposing the causes of educational failures in black primary schools, more and more articles were published and conferences centered on language in education policy. By the end of 1990, the language working group of the National Education Policy Investigation (NEPI) began its research. The ANC, unbanned but not yet in power, had its own education department which focused on language policy, among other important issues.

The National Language Project (NLP) and The Project For Alternative Education In South Africa (PRAESA), to name two, sponsored workshops within conferences and published articles and information concerning language policy toward the goal of public awareness of and wider public discourse on this 
issue. Since 1989, the NLP has been the focus of the most sustained work in the field of South African language policy formulation (Lowe, 1992). In 1995, the NLP and PRAESA published a resource book, Multilingual Education for South Africa, both for practitioners, making available experiences of innovative work done in multilingual classrooms, and for teacher-educators and educational planners. The book is further intended to contribute to the continuing debate about language in education policy.

What are the principles being set forth upon which a new language policy will be framed?

Tracing discussions in the government documents surveyed in this study though the first six years of the 1990's, I found tremendous consistency in the principles being set forth. I have grouped these expressed principles into the following general categories:

1. Multilingualism: Central to all other principles is the full commitment to supporting multilingualism in education. The Constitution declares eleven official languages, acknowledging and protecting the diversity of languages. Language in education policy would, therefore, need to support this central democratic principle. Further, the ANC supports the learning of two, preferably three languages in school. It supports institutional, i.e. school, university, etc., obligations to declare three languages and use all three in their operations. Multilingualism at individual, institutional and social levels is one of the key aims. Multilingualism promotes inclusiveness and, therefore, national unity, so this principle applied in education would relate to and support national goals. High proficiency in two, preferably three languages will facilitate communication among all South Africans, which also supports the goal of national unity. 
2. Redressing the past neglect of African languages: The government holds that it should take affirmative action to develop and promote the eleven official African languages previously disadvantaged and neglected, acknowledging that by doing so it would provide indirect influence over educational choice of particular languages. One action already taken is the creation of a language board, PANSALB, which, among other responsibilities, is to serve the interests of each of the official languages. The ANC recognizes a responsibility to come to terms with the hegemony of English. Redressing the imbalances of the past through incentives to choose African languages for study and wider use, public awareness programs, research and public expenditures for language development are a few methods mentioned. The ANC also notes that African languages are the primary linguistic resources of most South Africans, and that schools should build on the linguistic strengths that learners and teachers bring to the classroom. By proposing additive bilingual models, the government supports the greater utilization of African languages in school.

3. Language as a resource: The ANC recognizes African languages as a social resource. They have been denied or underutilized in education in particular and in national life in general. These resources should not be wasted but recognized in language in education policy for their inherent value and used effectively in the classroom. English, too, is a resource that should be made available to all learners in an improved way that empowers South Africans to participate in the social, economic and political life of their country. Language is key to learning, and, therefore, to long-term prospects of reconstruction and development.

4. Choice of languages: Freedom of choice is a principle for individual learners through choice of languages made on a local level. Since language is essential 
to thinking and learning, learners must be able to learn in the languages which best serve this purpose. The facilitation of individual choice and democratic decision-making is a priority. Coordination of choice at a level beyond the local school is essential.

5. Language as a right: Language rights, which are fundamental to human rights, must be protected in legislation, policy and practice. The Constitution gives rights to every person to instruction in the language of his or her choice, where this is reasonably practical. It provides for conditions to develop and promote the equal treatment and use and enjoyment of all official languages. Unfair discrimination on the grounds of language is unlawful.

6. Democratic governance: Democratic community structures involving all the affected constituencies should be responsible for shaping language policy on the local level within the broad guidelines of the Constitution and the criteria established by the Dept. of Education. Involvement on the grassroots level through the active support of parents, teachers, and students will help assure that language plans fit the local context.

7. Flexibility: Language policy must respond to a variety of needs and wishes of the citizens. The government supports creative options and multiple models. Language policy formation should be dynamic, cyclical and flexible to adapt to changing circumstances and respond sensitively to the needs and aspirations of the people it serves.

What models or options are being proposed, and what are their stated benefits and possible disadvantages?

Two non-governmental organizations, the National Language Project (NLP) and the Project for the Study of Alternative Education in South African 
(PRAESA), have taken a lead in proposing models which place a high value on the resources that languages unlock. The two NGO's are committed to language planning from below. They posit that a shift in paradigm from language as a problem and a right to language as a functional resource needs to take place (see Ruiz, 1988). They also recognize that a coherent national plan for languages in South Africa still needs to be developed. All stakeholders from government and the private sector need to come together taking joint responsibility for this coherent plan, which should be based on the three principles of access, equity, and economic growth (Heugh, 1995). Language cannot be addressed on a piecemeal basis in government sectors dealing with education, arts and culture if it is to be integrated in all aspects of national life.

The NLP and PRAESA support additive bilingual models in which the first language is maintained as the language of learning throughout, while a second and preferably a third is gradually introduced. Driving the additive bilingual model is the belief that bi-or multilingualism aids cognition, and that additive bilingualism is a better guarantee of the empowerment of all South Africans than the present subtractive bilingual model. Alongside the broader goal of facilitating multiculturalism nationwide and displacing discrimination based on language, the NGO's believe that the practical outcome of an additive bilingual model is the preparation of more competent learners of English among currently marginalized South Africans.

The NLP is looking to strategies which may transform the hegemony of English in the economy. Besides making logical sense to access the knowledge and experience which people have in languages other than English, which in South Africa would come from over $90 \%$ of the population, it makes financial 
sense to move away from present transitional and subtractive models which have wasted untold resources on unsuccessful programs.

The models are based on the recognition of three factors (Heugh, 1995):

1. because a large proportion of the population wants English to be the lingua franca, an effective model and implementation strategies, such as teacher training and deploying human and material resources where needed, need to provide real access to English,

2. the other South African languages have roles to play in the public and private sectors as provincial or national languages in government, economy and education, and

3. the hegemony of English needs to be contained and African languages need development so that the status of all languages is addressed and balanced.

The advantages of the additive bilingual model are many. The premises it is based on are positive in that they are democratic, inclusive, flexible, resourceful, open to change over time, cognitively beneficial and adaptable to different contexts and local interests.

A disadvantage is that the additive bilingual model is a significant change from the past, and change usually brings with it anxiety and resistance. A new model must be accompanied by related change outside the educational system for a real difference in student achievement to take place and endure. Another disadvantage is that it will require attitudes toward the relative value of English and African languages to change. Trust in educational reform will have to be rebuilt given the history of past 'reform', which disadvantaged black students. This model also requires a complete revamping of curriculum and teacher 
training; however, those elements are slated for major change regardless of what language policy is determined.

\section{What consensus is emerging, if any?}

In the government and education sectors, where the preponderance of work on developing a language in education policy has been done, there is clear consensus that all the above principles form an important foundation upon which educational success for all students, and thus for the country as a whole, can emerge. While there are differences among educationists and government policy makers in terms of focus and emphasis on these principles and how they might be applied in real settings, the foundation being laid in policy has a large constituency of support.

There are inherent tensions within the principles espoused above that need to be reconciled. The tensions include the conflict between developing and promoting previously disadvantaged languages, on the one hand, with the constitutionally prescribed non-diminution of rights relating to language and the status of languages existing at the passage of the Constitution. In other words, if the status of English and Afrikaans cannot be diminished, how can the status of African languages rise enough to be in balance with them? Another tension is the principle of choice which is constrained by the pragmatic requirements of the availability of human, material and financial resources. A third is that the principle of choice might conflict with affirmative action toward African languages (Dept. of Education, 1995).

Another critical component to consider in facilitating the success of a language policy, as measured by the ability to accomplish stated policy goals, is the policy's inclusion in a national development plan. If the policy is seen only 
relating to the domain of arts and culture and not related to economic growth, it can only be partially successful at best. If the national development plan is heavily influenced by western aid agencies, such as the World Bank, which in 1992 made it clear that it would not fund additive bilingual models (Heugh, 1995), success of a policy founded on the principles of multilingualism, choice of languages, and redress of the marginalization of African languages would be seriously compromised if not completely undermined.

What factors will affect the success of a language in education policy?

There have been many opinions and recommendations expressed in the literature I reviewed regarding the attributes and other factors that will help assure that a language policy meets its goals. Following is a selection of those factors I consider to be the most critical to account for when designing implementation plans for a new policy.

The South African government has launched many new initiatives to meet the enormous needs of deprived communities. In its effort to move fully toward the realization of a democratic society, the government must invite grassroots participation in decision making. What must accompany this invitation is an awareness campaign so that parents, teachers and community members will have a broad understanding of educational issues, including language issues, and how they relate to other societal needs and concerns. Since parents have historically had little to no control over school decisions, their involvement needs to be actively sought and valued. Political negotiation and acceptance of compromise must be understood to be critical components of decision making, since needs outstrip resources in the improvement of education. 
If multilingualism is to be successfully fostered in schools, multilingualism must be included and actively pursued in a national development plan. Without the use of African languages in many domains of political, economic and social institutions, English will continue to dominate the classroom and marginalization of African languages will be further reinforced. There must be motivation to leave the status quo where English dominates. Multilingualism may be resisted by elites or others, but continual forward movement toward the goal of multilingualism in school in concert with multilingualism in the important domains of national life can help change entrenched language attitudes which favor English to the detriment of other languages.

Teachers who are properly trained will make an enormous difference in the lives of their students. Furthermore, if they are given the tools, support and encouragement to take leadership roles in making change, they can become role models for students and adults. Language teaching theory and methodology must not only be appropriate to the South African context, but curriculum changes must take into account medium of instruction issues and articulation of the learning of two or more languages.

Flexibility is key because local conditions vary greatly and situations vary over time. Responsible innovation and collegial sharing should be supported, with various models and demonstration schools evaluated for their effectiveness. Implementation procedures for language teaching should be realistic, resource-sensitive and treat groups fairly. There should be substantial bottom-up decision making regarding the appropriateness of implementation plans in a given local context. Communities should not expect the government alone to carry the responsibility for making changes in schools. 
The last factor mentioned here is one less tangible but 1 believe critical to the welfare of the child and community, and that is the validation of the child and the knowledge, value system, history and culture that the child brings to school. Teaching through the child's language acknowledges his or her culture as important. In this regard, any of the multilingual models cited in this study can succeed given acceptance in the school community and appropriate support and evaluation. It is not so critical which model is selected as long as it is appropriate to the local situation where the teachers are properly trained to work in the model and, just as important, there is a willingness on the part of parents, students and teachers to make this model succeed. This willingness will only come about if the school community believes that the children will have a better economic future with this kind of education than with an all-English one. Furthermore, I believe a multilingual model can be an important step toward removing cultural and linguistic marginalization from the daily lives of South Africa's new citizens.

\section{SUGGESTIONS FOR FURTHER RESEARCH}

The issue of language in education policy in South Africa is not likely to be resolved soon, and the government's intention is that the policy remain open to change over time and refinement. It is a complex issue that can be researched in its many component parts. Issues that are mentioned in Limitations of the Study can be researched. Implementation plans and model schools can be studied. A thorough study would be difficult to accomplish without one or more sources in South Africa willing and able to supply the breadth and depth 
of literature to support the study, as most of these materials are not as yet catalogued in information systems in the way they are in American university libraries. A visit to South Africa is very important in order for the researcher to put these readings in a cultural context.

Language policy is a continuing and contentious issue in the United States and in its individual states. A researcher could study the change or attempted change in language policy in a state by looking at the historical beginnings of and status of languages in a state, and the issues that are bringing about desired change in policy on the part of one or more factions. The English Only movement could be studied in a broad perspective of how it formed and who are the parties in and outside of the movement and their positions. Another more focused look at some aspect of English Only could be taken from a legal, cultural, or educational perspective, for example.

\section{IMPLICATIONS FOR THE TESOL PRACTITIONER}

This research was undertaken on Schmied's (1991) premise that the quality of English teaching is decidedly influenced by factors outside both the language and the educational system. Awareness of language policy on a governmental and institutional level is beneficial to both the TESOL practitioner and to the students he or she teaches.

Though language rights are not addressed expressly in the U.S. Constitution, there is case law and state law and policies that call for provision of language support in certain educational settings. To be aware of these policies and rights allows the ESL teacher to take appropriate action on behalf of students when policies are poorly implemented or ignored. The teacher is 
also in a position to propose needed policy change, as administrators too often neglect this area of education in their multiple responsibilities. When there are perceived threats to linguistic pluralism, the teacher can provide an informed and reasoned voice to the policy debate.

When teaching abroad, a teacher's awareness of the national situation as it affects language use would seem to be fundamental to the choices made for the classroom. In addition, an institution's policies, goals and restrictions concerning English language teaching are important for the teacher to know to fulfill the terms of the teaching contract. However, the teacher should also be aware of tensions that may exist between students' language needs, institutional policies, if they exist, national language policies, if they exist, and the sociolinguistic context of the locale. All of these sources will inform the teacher who can then make the best and most appropriate choices in that particular circumstance for what and how to teach in the classroom.

\section{CONCLUDING THOUGHTS}

It is important to reiterate that language policy must be applied in the context of political, economic and social realities. It must take into account the historical past, present attitudes toward language, and visions for the future. South Africa has embarked on the difficult journey of transforming the societal institutions which were structured on unjust and undemocratic principles. In relation to many of its African neighbors, South Africa is in an enviable position, possessing wealth in its natural and human resources and expertise in all fields across the board. Still, it is a daunting challenge to scrap a badly conceived social organization such as its present school system and replace it with a 
system that serves all students and teachers equitably, while redressing past injustices. It requires strong political will and continual compromise, clear and consistent communication among education constituencies, widespread grassroots involvement, and attention to both immediate needs and distant goals. 


\section{REERENCES}

Alexander, N. (1995). Models of multilingual schooling for a democratic South Africa. In K. Heugh, A. Siegrühn, \& P. Plüddemann (Eds.), Multilingual Education For South Africa (pp. 83-88). Johannesburg: Heinemann Publishers (Pty) Ltd.

Alexander, N. \& Smolicz, J. (1993). The quest for core culture. Bua! 8(3), 4-8. ANC (1993). Language policy in education. Johannesburg: ANC.

ANC (1994). Lanquage curriculum framework for compulsory education. Johannesburg: ANC.

Bamgbose, A. (1995). Nigeria's choice. Bua! 10(1), 24-26.

Bosch, B. \& de Klerk, V. (1996). Language attitudes in the Eastern Cape. In V. de Klerk, (Ed.), Focus on South Africa.(pp. 231-250). Philadelphia: John Benjamins Publishing Co.

Chinyakata, R. (1994, August 21). Do we really need English? Sunday Gazette, Harare, Zimbabwe. In Bua! 9(3), 25.

Christie, P. (1991). The right to learn: the struggle for education in South Africa. Johannesburg: SACHED Trust.

Cluver, A. (1992). Language planning models for a post-apartheid South Africa. Language Problems and Language Planning.16(2), 105-136. Amsterdam: John Benjamins Publishing Co.

Cooper, R. (1989) Language planning and social change. Cambridge: Cambridge University Press.

Core Syllabus Committee for English (1993). An initial investigation into the teaching and learning of English in primary and secondary schools in South Africa in 1993. Unpublished survey.

Crawhall, N. (1993). Negotiations and language policy options in South Africa. Cape Town: National Language Project. 
Department of Education, Republic of South Africa (1995, November). Towards a language policy in education. Government discussion document. Pretoria: Minister of Education.

Department of National Education, Republic of South Africa (1993). South Africa's new lanquage policy. Pretoria: Minister of Education.

Gordon, F. \& Barkhuizen, G. (1994). Alienation and conflict in an open primary school: A mulitilingual setting. South African Journal of Applied Language Studies. 3(1), 60-76.

Gough, D. (1994). Myths of multilingualism: Demography and democracy. Bua!9(3), 9-11.

Harlech-Jones, B. (1990, May). English in Namibia. Crux. pp.43-49.

Harlech-Jones, B. (1994). Language policy for a multilingual society. Paper presented at the Fourth National Conference of SATESOL, University of the North, South Africa.

Hartshorne, K. (1995). Language policy in African education: A background to the future. In R. Mesthrie, (Ed.), Lanquage and social history: Studies in South African sociolinguistics (pp. 306-318). Cape Town: David Philip.

Heugh, K. (1995). Disabling and enabling: Implications of language policy trends in South Africa. In R. Mesthrie, (Ed.), Language and social history: Studies in South African sociolinguistics (pp. 329-351). Cape Town: David Philip.

Heugh, K. (1995a). A whole new board game. Bua! 10(1), 20-21.

Heugh, K. (1995b). The multilingual school: Modified dual medium. In K. Heugh, A. Siegrühn, \& P. Plüddemann (Eds.), Multilingual Education For South Africa (pp.83-88). Johannesburg: Heinemann Publishing (Pty) Ltd.

Heugh, K. (1995c). From unequal education to the real thing. In K. Heugh, A. Siegrühn, \& P. Plüddemann (Eds.), Multilingual Education For South Africa (pp.83-88). Johannesburg: Heinemann Publishing (Pty) Ltd.

Heugh, K., Siegrühn, A., \& Plüddemann, P. (Eds.) (1995). Multilingual Education For South Atrica. Johannesburg: Heinemann Publishing (Pty) Ltd. 
Hughes, P., Corson, D., \& Caldwell, B. (1985). Interface between education and state policy: Australia. Bangkok: UNESCO.

Janks, H. (1990). Contested terrain: English education in South Africa 19481987. In I. Goodson \& P. Medway (Eds.), Bringing English to order (pp. 242-261). Philadelphia: Falmer Press.

Jenkins, E. (1991). Language planning in South Africa. English Academy Review (P8), 127-134.

Kashoki, M. (1994). A battle lost in the frontline. Africa Insight. 24(4), 287-292.

Lemmer, E. (1993). Addressing the needs of the black child with a limited language proficiency in the medium of instruction. In J. le Roux (Ed.) The black child in crisis: A socio-educational perspective (pp. 144-169). Pretoria: J.L. Van Schaik (Pty) Ltd.

Louw, P. (1992). Language and national unity in a post-apartheid South Africa. Critical Arts 6(1), 52-60.

Louw-Potgieter, J. \& Louw, J. (1991). Language planning: Preferences of a group of South African students. S.A. Tydskrif vir Taalkunde 9(4), 96-99.

Luckett, K. (1993). "National additive bilingualism": towards the formulation of a language plan for South African schools. Southern African Journal of Applied Language Studies. 2(1), 38-60.

Luckett, K. (1995). National additive bilingualism: Towards a language plan for South African education. In K. Heugh, A. Siegrühn, \& P. Plüddemann (Eds.), Multilingual Education For South Africa. (pp.73-78). Johannesburg: Heinemann Publishing (Pty) Ltd.

Macdonald, C. (1990). How many years do you have? English language skills evaluation. a final report of the threshold project. Pretoria: Human Sciences Research Council. (ERIC Document Reproduction Service No. ED344468).

Macdonald, C. (1990a). Crossing the threshold into standard three in black education. the consolidated main report of the threshold project. Pretoria: Human Sciences Research Council. (ERIC Document Reproduction Service No. ED344469).

Macdonald, C. \& Burroughs, E. (1991). Eager to talk and learn and think: Bilingual primary education in South Africa. Cape Town: Maskew Miller Longman. 
Mandela, W. (1995). Winnie Mandela speaks. Bua! 9(2),6-7.

Msimang, C. (1996). Towards a linguistic policy for UNISA. the case for African languages. Pretoria: UNISA.

Murray, S. \& van der Mescht, H. (1996). Teaching English as L1 and L2. In de Klerk (Ed.). Focus on South Africa.(pp. 250-260). Philadelphia: John Benjamins Publishing Co.

NEPI (1992). Language. Cape Town: National Education Coordinating Committee and Oxford University Press.

NEPI (1993). The framework report and final report summaries. Cape Town: National Education Coordinating Committee and Oxford University Press.

Ndebele, N. (1987). The English language and social change in South Africa. English Academy Review.4, 1-16.

Pattanayak, D. (1985). Educational use of the mother tongue. In B. Spolsky (Ed.), Language and education in multicultural settings (pp. 5-14). San Diego: College-Hill Press.

Paulston, C. (1986). Linguistic consequences of ethnicity and nationalism in multilingual settings. In B. Spolsky (Ed.) Lanquage and education in multicultural settings (pp. 117-143). San Diego: College-Hill Press.

Paulston, C. (1994). Linguistic minorities in multilingual settings: Implications for language policies. Philadelphia: J. Benjamins Publishing Co.

Phillipson, R., Skutnabb-Kangas, T., \& Africa, H. (1986). Namibian educational language planning: English for liberation or neo-colonialism? In B. Spolsky (Ed.) Language and education in multicultural settings (pp. 77-95). San Diego: College-Hill Press.

Plüddemann, P. (1995). Girls go for Xhosa. Bua! 10(1) p.15.

Reagan, T. (1995). Language planning and language policy in South Africa: a perspective on the future. In R. Mesthrie, (Ed.), Language and social history: studies in South African sociolinguistics Cape Town: David Philip.

Ruiz, R. (1988). Orientations in language planning. In S. McKay, \& S. Wong, (Eds.), Language Diversity-Problem or Resource? Cambridge: Newbury House. 
Schmied, J. (1991). English in Africa: An introduction. New York: Longman.

Smith, F. (1993). Whose language? what power? A universal conflict in a South African setting. New York: Teachers College Press.

Sqelch, J. (1993). Towards a multicultural approach to education in South Africa. In J. le Roux (Ed.) The black child in crisis: a socio-educational perspective (pp.174-201). Pretoria: J.L. Van Schaik (Pty) Ltd.

South African Institute of Race Relations (1994). Race relations survey 1993/4. Johannesburg: South African Institute of Race Relations.

Teach in English, says the ANC. (1993, April 4), Weekend Argus, p.15.

Titlestad, P. (1996). English, the constitution and South Africa's language future. In V. de Klerk, (Ed.), Focus on South Africa (pp.163-174). Philadelphia: John Benjamins Publishing Co.

Tollefson, J. (1991). Planning language, planning inequality. London: Longman.

Wade, J. (1993). Stoking the third world express: The politics of cultural transformation. English in Africa .20(1), 55.

Walters, P. (1996). Issues in English teaching in black primary schools. In de V. Klerk, (Ed.), Focus on South Africa (pp.211-230). Philadelphia: John Benjamins Publishing Co.

Webb, V. (1994). Language policy and planning in South Africa. In W. Grabe (Ed.) Annual Review of Applied Linguistics (pp. 254-276). Cambridge: Cambridge University Press.

Webb, V. (1996). English and language planning for South Africa. In V. de Klerk, (Ed.), Focus on South Africa (pp.175-190). Philadelphia: John Benjamins Publishing Co.

World Bank (1988). Education in sub-Saharan Africa: Policies for adjustment revitalization, and expansion. Washington, D.C.: The World Bank.

What the ANC is calling for. (1993, April 30). Mayibuye. 4(3) p.24.

Wright, L. (1993, Dec.). English in South Africa: Effective communication and the policy debate. English Academy Review, pp1-13. 
147

Zuengler, J. (1985). Language of instruction in Kenya and Tanzania. In N. Wolfson and J. Manes (Eds.), Language of inequality. (pp.) New York: Mouton. 